\title{
ECONOMIC EVALUATION GUIDE for Alternative Transportation Fuels
}

Prepared for:

Alternative Vehicle. Fuels Core Assistance Program of the Urban Consortium Energy Task Force 1301 Pennsylvania Avenue, NW

Washington, DC 20004-1793

$202 / 626.2441$

Prepared by:

Denise de Percin

Jack F. Werner, Jr.

Public Technology, Inc.

1301 Pennsylvania Avenue, NW

Washington, DC 20004-1793

202/626-2441 


\section{Acknowledgements}

This guidebook is one of a series of products and activities supported by the Alternative Vehicle Fuels Core Assistance Program (AVFCAP), the Urban Consortium Energy Task Force, and Public Technology, Inc. (PTI). Denise de Percin and Jack Werner, from PTI, are responsible for the writing of this guide and general day-to-day management of the AVFCAP program.

Compilation of this Economic Evaluation Guide would not have been possible without the assistance of many people. Thanks go to all the members of the Urban Consortium Energy Task Force (UCETF) Alternative Vehicle Fuels and Technologies Unit, who provided feedback and advice; the AVF Unit private sector partners, who provided financial support for the AVFCAP program; and the Management Committee of AVFCAP, for their guidance. Special thanks go to the co-managers of the AVF Unit, Creighton Lederer, Detroit, MI, and Chuck Clinton, Washington, DC. 
iv Economic Evaluation Guide for Hiernative Transportation Fuels 


\section{Preface}

Alternative transportation fuels are receiving regulatory promotion on several governmental levels as a means of improving air quality, increasing our energy security, and reducing energy costs. The Alternative Motor Fuels Act of 1988 contains provisions to stimulate the supply and use of alcohol, natural gas, and electric vehicles. The 1990 Clean Air Act Amendments contain provisions that promote the use of cleaner fuels in regions with the greatest non-attainment of National Ambient Air Quality Standards. The National Energy Strategy calls for the use of alternative transportation fuels as part of a comprehensive plan for energy use. The Intermodal Surface Transportation Efficiency Act (ISTEA) passed by Congress in December 1991, gives cities and counties greater flexibility in allocating federal funds for local transportation priorities, and includes a specific program to address air quality issues.

On the state level, Texas and California are aggressively promoting the use of alternative transportation fuels. Texas has recently adopted legislation requiring the use of these fuels in public and private fleets through the 1990s. The 1990 California Clean Fuels Regulations set emissions standards that are more stringent than federal standards, and it has developed a schedule for the phase-in of vehicles with low, ultra-low, and zero emissions.

The Northeastern states of Maine, Massachusetts, New Hampshire, New Jersey, Rhode Island and Vermont have agreed to adopt emissions standards similar to California's. States throughout the Midwest and West, including Arizona, Colorado, Nebraska, and South Dakota, have adopted legislation ranging from 
the mandated use of oxygenates in gasoline to reduced registration fees for alternatively-fueled vehicles.

Private and public promotion measures are encouraging public fleet managers to examine their options to determine which alternative transportation fuels are best for their particular circumstances. The purpose of the Alternative Vehicle Fuels Core Assistance Program is to provide fuel-neutral information to be used as one component in a comprehensive decision process.

The pages that follow are intended to outline for fleet managers the economic issues that must be considered when choosing among alternative fuels. 


\section{Contents}

Acknowledgements

Preface

1.0 Overview

1.1 Introduction

1.2 Outline

Endnote

2.0 Framework

2.1 Introduction

2.2 Matrix

Endnotes

\subsection{Direct Costs}

3.1 Capital Costs

3.2 Operating Costs

3.3 Lifecycle Costs

Endnotes

4.0 Indirect Costs

4.1 Regulatory Costs $\quad 23$

4.2 Institutional Costs 26

4.3 Societal Costs 28

Endnotes 30

5.0 Cost Comparisons $\quad 31$

5.1 Lifecycle Costs 31

5.2 Balancing the Costs 32

5.3 Comparisons With Petroleum Fuels 33 
6.0 Financial Decisions

6.1 Alternative Fuels and Duty Cycles

6.2 Vehicle Options

6.3 Infrastructure Options

7.0 Conclusion

7.1 International Considerations

7.2 National Considerations

7.3 Local Considerations Endnote

Appendix A

AVFCAP Management Committee

Appendix B

List of Related UCETF Reports

Appendix C

AVF Economic Evaluation Scenarios 


\subsection{Overview}

\subsection{Introduction}

Alternative transportation fuels (ATFs) offer the strong potential to aid in reducing U.S. dependence on foreign oil supplies, with the concomitant benefits of decreased air pollution and stabilized fuel costs in urban areas. These fuels - which include electricity, natural gas, propane, methanol, hydrogen, and ethanol have captured only a small share of local government markets in the U.S. Local governments can play an instrumental role in realizing these benefits through practical development and highly visible demonstrations of alternative transportation fuels and technology options.

Recent legislative and regulatory initiatives by the Bush Administration, by Congress, and increasingly by state and local authorities, emphasize the growing importance of ATFs through the end of this century and beyond. The non-attainment cities mentioned in the Clean Air Act, as well as other major urban areas around the country, will be the leaders in testing ATFs and developing the infrastructure required to make them a viable transportation option.

For these reasons, the Urban Consortium Energy Task Force (UCETF) has organized a specially designed applied research and demonstration program to address alternative transportation fuels. Begun formally in October 1988, this program consists of local governments participating in direct partnership with energy utilities, fuel suppliers, manufacturers, research organizations, and 
"Recent legislative and regulatory initiatives by the Bush Administration, by Congress, and increasingly by state and local authorities, emphasize the gr $x_{i} \rightarrow$ ing importance of ATFs through the end of this century and beyond."
ATF associations. Primery financial support for city and county staff is provided by the UCETF; utility partners contribute both direct financial and technical support. To assure an effective administrative structure, the program is under the overall guidance of a management committee that consists of representatives from the membership of the UCETF, the Natural Gas Vehicle Coalition, the Electric Vehicle Association of the Americas, the Solar Energy Research Institute, Ford Motor Company, National Association of Fleet Administrators, Inc. (NAFA), and Public Technology, Inc. (PTI).

Important services for participating jurisdictions and for the collective projects in the Alternative Fuels and Technologies Unit are provided through the Alternative Vehicle Fuels Core Assistance Program (AVFCAP), managed by PTI. Activities within AVFCAP are designed to improve resource and information bases, provide coherent technical support, aid in the transfer of program results, and identify and develop Public Enterprise opportunities in the field of ATFs. AVFCAP is made possible by contributions of direct financial aid and in-kind assistance from the unit's private sector project partners. Additional support is provided by industry associations and staff from several of the Department of Energy's (DOE) national laboratories.

The production of this Economic Evaluation Guide is one activity of AVFCAP. The guide is intended for use by project managers and fleet operators in the public sector. Public fleets have been identified as one of the most likely areas where ATFs will first gain widespread use, because of existing and impending state and federal legislative mandates, as well as for practical reasons such as centralized servicing and refueling. The purpose of this guide is to provide balanced decision-support information to project managers who are considering conducting, or currently managing, ATF demonstration programs. Information for this guide was gathered as part of a related AVFCAP activity, the development of an Information Resource Database. ${ }^{1}$

Economic issues related to the development and implementation of ATF programs at the local government level are extremely complex, and require an analysis of federal policies and national and international economics that is generally beyond the scope of local government project managers. The intent of this guide is to examine the information available on the economic evaluation of ATFs, and identify key elements that will help local governments realistically assess the potential costs and savings of an ATF program. The guide also discusses how these various economic factors are related, and how local government priorities affect how different factors are weighed. 
Ultimately, each local government must develop a program that is particularly suited to its needs and resources. A wide range of factors, including, but not limited to, economic analysis, will determine the choice each jurisdiction makes regarding alternative fuels for their fleets.

\subsection{Outline}

Our discussions in this report are generally limited to the three alternative fuels that have figured most prominently in the national discussions about clean air and alternative fuels: compressed natural gas (CNF;, electricity, and methanol.

The report is divided into seven major sections, as follows:

- Overview

- Framework

- Direct Costs

- Indirect Costs

- Cost Comparisons

- Financial Decisions

- Summary and Conclusions.

The first section describus the UCETF, PTI, and the ATF program. It also includes a descriptive outline of this report.

Section two provides a framework of the factors involved in the economic analysis of ATFs as compared to conventional fuels. It includes a matrix summary of economic elements that are discussed in later sections.

Sections three and four cover the direct (internal) and indirect (external, or nonmarket) costs of implementing and operating an ATF program.

The fifth section discusses some of the issues involved with making cost comparisons between different types of alternative fuels, as well as the problems involved with comparing the infant technologies used in alternative transportation fuels with a relatively mature and well-established petroleum fuel industry.

The sixth section raises additional non-quantitative factors that affect the financial decisions made by local governments in choosing one or several ATFs.

The last section addresses the national and international agendas related to clean air, and how they affect local governments. It also discusses further the issue of local government priorities, and how ATFs can help them attain their goals. 


\section{Endnote}

${ }^{1}$ Access to the Information Resource Database will be available through Local Exchange, the online computer network and database operated for local governments by the National League of Cities, the International City/County Management Association, and PTI.

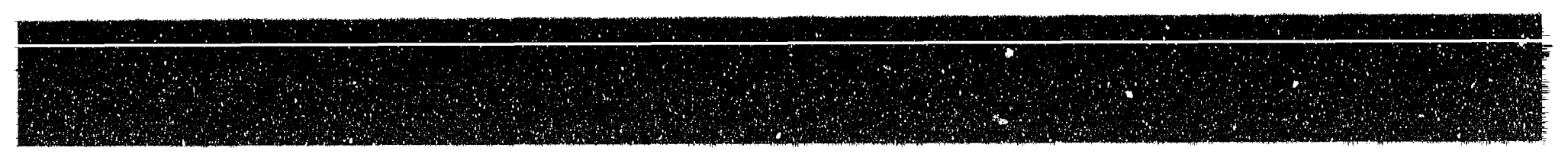




\subsection{Framework}

\subsection{Introduction}

The motivation for much of the legislation and regulation of ATFs on a federal and state level is concern about the environmental impact of mobile source emissions on air quality. A second motivation, in light of our increasing dependence on foreign sources for petroleum fuels, is the need for energy security. For local governments in particular, there is a third consideration that is at minimum, equaliy important: the economic impact of developing and using ATFs.

This guide approaches the economic evaluation of ATFs by assigning the associated costs into one of two categories: direct and indirect. Direct costs are the calculated and quantifiable expenses required to purchase and operate an alternatively-fueled vehicle, including capital costs, operating costs, and lifecycle costs. Indirect costs are secondary and higher costs associated with the use of alternatively-fueled vehicles that affect the overall economic equation. How these two different types of costs are weighed depends on the motivation for considering ATF use, and how the different "drivers" mentioned above - air quality, energy security, and economic advantages - are integrated. Some of the costs may be relevant to more than one category.

Reproduced in Appendix $\mathrm{C}$ are tables showing economic analyses of several alternative fuels. ${ }^{1}$ These different scenarios are excellent examples of how the economic factors included in the matrix (figure 1) can be assessed. However, it is clear from the 
disparity in the figures developed using different methods and sources that there is no firm consensus on the reasonable assumptions and input values used in these calculations. Furthermore, in order for an economic evaluation to be useful on a local level, it must be sensitive to regional factors in a way that no general analysis could.

\subsection{Matrix}

What follows is a matrix of the economic factors affecting alternative fuel choice based upon a review of the literature and experience with UCETF and other ATF demonstration programs. The purpose of the matrix is to give an overview of the economic issues involved in an evaluation of ATFs, prior to discussing them in more detail in sections Three and Four. The matrix is intended as a tool to assist project managers a seet operators in developing an alternatively-fueled vehicle program that is suited to their needs and is economically viable. ${ }^{2}$

\section{Endnotes}

'See also the New York City's UCETF Report, "Alternative Fuels: Infrastructure Issues," listed in Appendix B.

${ }^{2}$ See also Denver's UCETF Report, "An Alternative Fuels Evaluation System for Fleet Vehicles," listed in Appendix B. 


\section{Figure 1. ECONOMIC EVALUATION MATRIX}

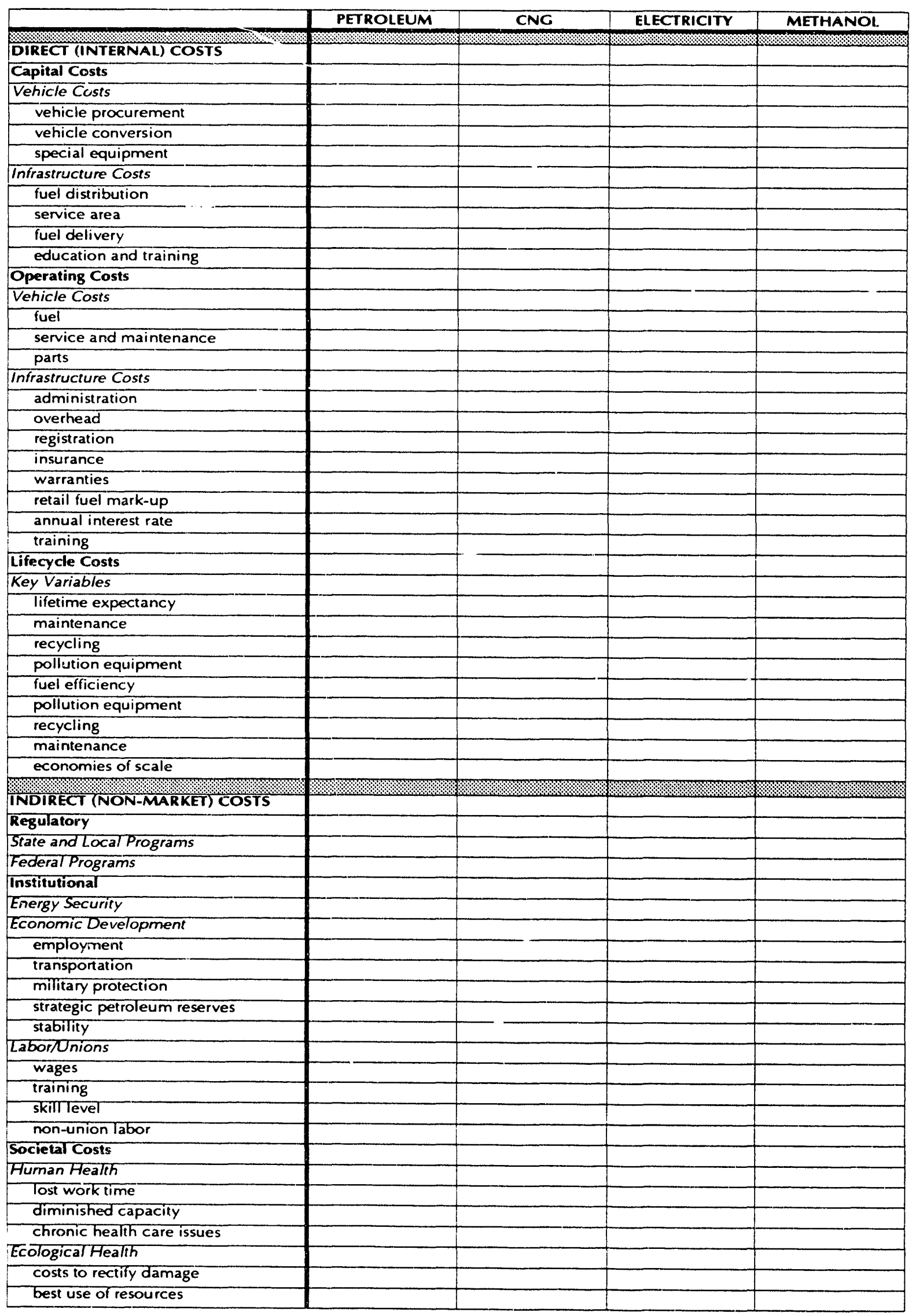


8 Economic Evaluation Guide for Alternative Transportation Fuels

ECONOMIC EVALUATION MATRIX

\begin{tabular}{|c|c|c|c|c|}
\hline & DIESEL & PROPANE & ETHANOL & HYDROGEN \\
\hline \multicolumn{5}{|c|}{ DTRECT (INTERNAL) COSTS } \\
\hline \multicolumn{5}{|c|}{ Capital Costs } \\
\hline \multicolumn{5}{|l|}{ Vehicle Costs } \\
\hline \multicolumn{5}{|l|}{ vehicle procurement } \\
\hline \multicolumn{5}{|l|}{ vehicle conversion } \\
\hline \multicolumn{5}{|l|}{ special equipment } \\
\hline \multicolumn{5}{|l|}{ Infrastructure Costs } \\
\hline \multicolumn{5}{|l|}{ fuel distribution } \\
\hline \multicolumn{5}{|l|}{ service area } \\
\hline \multicolumn{5}{|l|}{ fuel delivery } \\
\hline \multicolumn{5}{|l|}{ education and training } \\
\hline \multicolumn{5}{|l|}{ Operating Costs } \\
\hline \multicolumn{5}{|l|}{ Vehicle Costs } \\
\hline \multicolumn{5}{|l|}{ fuel } \\
\hline \multicolumn{5}{|l|}{ service and maintenance } \\
\hline \multicolumn{5}{|l|}{ parts } \\
\hline \multicolumn{5}{|l|}{ Infrastructure Costs } \\
\hline administration & & & & \\
\hline overhead & & & & \\
\hline registration & & & & \\
\hline insurance & & & & \\
\hline warranties & & & & \\
\hline retail fuel mark up & & & & \\
\hline annual interest rate & & & & \\
\hline training & & & & \\
\hline Lifecyce Costs & & & & \\
\hline Key Variables & & & & \\
\hline Tifetime expectancy & & & & \\
\hline maintenance & & & & \\
\hline recycling & & & & \\
\hline pollution equipment & & & & \\
\hline fuel efficiency & & & & \\
\hline economies of scale & & & & \\
\hline (10006, & & & & \\
\hline INDIRECT (NON-MARKE & & & & \\
\hline Regulatory & & & & \\
\hline State and Local Programs & & & & \\
\hline Federal Programs & & & & \\
\hline Institutional & & & & \\
\hline Energy Security & & & & \\
\hline Economic Development & & & & \\
\hline employment & & & & \\
\hline transportation & & & & \\
\hline military protection & & & & \\
\hline strategic petroleum rest & & & & \\
\hline stability & & & & \\
\hline Labor/Unions & & & & \\
\hline wages & & & & \\
\hline training & & & & \\
\hline skill level & & & & \\
\hline non-union labor & & & & \\
\hline Societal Costs & & & & \\
\hline Human Health & & & & \\
\hline lost work time & & & & \\
\hline diminished capacity & & & & \\
\hline chronic health care isst & & & & \\
\hline Ecological Health & & & & \\
\hline costs to rectify damage & & & & \\
\hline best use of resources & & & & \\
\hline
\end{tabular}




\subsection{Direct Costs}

The quantifiable costs required to purchase and operate an alternatively-fueled vehicle are known as the direct or internal costs. Direct costs are usually expressed in simple quantified terms; however, the methods for calculating these costs can be quite complicated. Furthermore, because there is no consensus within the field of alternative fuels on the correct assumptions and variables used to determine these costs, they have a very wide range of values.

Direct costs for any vehicle fall into three categories: capital costs, operating costs, and lifecycle costs. Some expenses, such as the price of fuel, maintenance costs, and resale value of the vehicle are familiar because they parallel costs required for petroleum fueled vehicles. This section focuses on the direct

"Furthermore, because there is no consensus within the field of alternative fuels on the correct assumptions and variables used to determine these costs, they have a very wide range of values." costs associated with ATFs that are different from conventional expenses, and may be overlooked by an project manager unfamiliar with these fuels.

\subsection{Capital Costs}

The initial "one time" investment required to purchase a vehicle and establish a service and fueling station is known as the capital cost. Today, most alternatively-fueled vehicles are a specially manufactured "new technology," or converted OEM (original engine manufacturer) vehicles, and are not mass produced. Consequently, these "up front" costs are considerably higher for alternatively-fueled vehicles than for petroleum or diesel fueled vehicles. The cost difference between fuels depends on many factors, including the type of technology, the level of market 
penetration, and subsidies or discounts that may be available through special partnership and financing arrangements.

Vebicle Costs. These costs will depend largely on two factors: the choice of fuel and technology. Three expenses must be considered:

- procurement costs

- adaptation or conversion costs

- special features or equipment required.

For all fuel types, special features or equipment for the vehicles may be required as per the manufacturer's or converter's recommendation, or to meet user needs. Particularly for ccnverted vehicles, the fuel tanks or battery packs may take up a significant amount of storage space in the vehicle. These vehicles may need to be equipped with extra storage space.

Below, we will discuss briefly the expenses that need to be considered for each major ATF.

CNG: Most CNG vehicles in use today are conventionally manufactured vehicles that have been converted to run on CNG using a retrofit kit. ${ }^{1}$ Converted vehicles may run on CNG exclusively (a "dedicated" vehicle), or on CNG or petroleum on demand (a "bi-fuel" vehicle). In either case, the initial costs will have to include the price of the vehicle, plus the cost of the conversion kit, labor required to have the kit installed, and other adjustments required to enable the vehicle to operate on the CNG. If more than a few vehicles are to be converted, at least one fleet mechanic should be trained to perform the conversions on site. This generally represents a significant savings in time, money, and repairs over the long run. ${ }^{2}$

Electricity: In contrast to CNG, most electric vehicles (EVs) are available as OEM, or are converted by a manufacturer prior to purchase. The cost of this conversion is included in the price of the vehicle. If the battery packs are included as well, this generally makes the purchase price of an EV considerably higher than the cost of a petroleum fueled vehicle. Although the high price can be a barrier to purchasing, particularly with budgeting and procurement regulations, the entire lifecycle costs of an EV, or any vehicle, should be considered before deciding on its economic viability. Because EVs do not use an internal combustion engine (ICE), they are available almost exclusively as dedicatedfuel vehicles. Some hybrid EVs, which use small auxiliary motors to increase their range, have been produced. 
"Because ATFs are not yet fully commercial technologies, there is no welldeveloped system of fuel delivery and service; in most cases, the infrastructure must be built from scratch. The establishment of this infrastructure is complicated by the fact that it is very likely that several alternative fuels will develop and enter the market simultane "sly."
Methanol: Methanol can be used in vehicles in several different ways, consequently there are several different types of vehicles adapted for its use. A conventional vehicle can run on a mixture of up to $15 \%$ methanol and petroleum fuel with few, if any, adjustments required. Methanol vehicles, fitted with non-corrosive parts, may be designed to run on neat or nearly-neat methanol, or methyl tertiary butyl ether (MTBE), which is approximately $85 \%$ methanol and $15 \%$ gasoline. Lastly, under development is a generation of "flexible-fueled" vehicles, that can run on any mixture of fuels from $100 \%$ gasoline to $100 \%$ methanol. None of these vehicles require the purchaser to incur costs for converting the vehicle. In the first case, no conversion is required; in the second and third cases, the vehicle would either be OEM or would be previously converted by the provider.

Infrastructure costs. The capital costs required to develop the infrastructure necessary to service and fuel alternatively-fueled vehicles can be substantial. We are accustomed to an established transportation system that includes all the mechanisms necessary for the delivery of fuels. Because ATFs are not yet fully commercial technologies, there is no well-developed system of fuel delivery and service; in most cases, the infrastructure must be built from scratch. The establishment of this infrastructure is complicated by the fact that it is very likely that several alternative fuels will develop and enter the market simultaneously. Public and private fleet vehicles have been targeted as an optimal place to begin to build this infrastructure, because in general they are serviced and fueled at one centralized location.

Although capital investment for the infrastructure development may vary widely between different fuel types, all will include the following costs:

- fuel distribution system (getting the fuel to the station or refueling area)

- fuel station or special service area (land, buildings, equipment)

- fuel delivery system (getting the fuel to the vehicle)

- initial education and training (management, mechanics, operators).

Fuel distribution system. Costs associated with the fuel distribution system will be closely linked to regional factors. Ideally, the choice of fuel by a jurisdiction should reflect the availability of the fuel type and its relative cost in that location, among other factors. ${ }^{3}$ 
CNG: Several factors need to be examined in determining the cost of the fuel delivery system for CNG. First and foremost, as indicated above, gas pipelines should be accessible in the jurisdiction. An analysis of the capacity of the pipelines, the amount of reserves in a jurisdiction, and the peak demand for gas should be carried out to determine if the gas supply is adequate to meet the projected increase in demand caused by the conversion of fleet vehicles to CNG. ${ }^{4}$ If there is sufficient pipeline capacity, the cost must be calculated to run additional pipe to the desired location of the service station or stations. Inlet pressure off the supply pipe will also be significant in determining operating and lifecycle costs; this is discussed in subsequent sections.

Natural gas can also be delivered to fueling stations via specially designed tanker trucks that transport the natural gas already compressed, and feed it into storage tanks. This system eliminates or minimizes the need for a compressor at the fueling station, and may be particularly useful in situations where a mobile or temporary refueling station is needed.

Electricity: Electricity is generally available in all jurisdictions, so accessibility is not a problem. The source of the electricity may be conventional or non-conventional - such as solar. Rewiring for adequate voltage and power may be required, depending on the size of the fleet and when the vehicles will be recharged. Costs associated with the delivery of electricity to a service area generally tend to be lower than delivery of other ATFs or conventional fuels.

Methanol: The delivery of methanol is possible by pipeline, and may be viable over long distances to areas of high demand; however, most methanol is currently transported as a liquid by truck. The economic viability of methanol distribution will depend largely on the proximity of methanol supply and the amounts required. ${ }^{5}$ Transportation costs for methanol, once purchased, should be roughly equivalent to conventional gasoline per unit of polume. However, methanol has about half the energy density of conventional fuel, close to twice as much methanol would need to be transported to operate a fleet comparable distances. This would result in higher overall transportation costs when compared with conventional fuels.

It should be noted that for liquid fuels (petroleum, methanol, diesel) used with a conventional delivery system, up to one-third of the fuel can be lost in running loss emissions and evaporative emissions during storage and refueling. Fuels that use a closed fueling system (CNG, propane, electricity) do not incur this loss. This can translate into savings in fuel transportation and 
"It should be noted that for liquid fuels (petroleum, methanol, diesel) used with a conventional delivery system, up to one-third of the fuel can be lost in running loss emissions and evaporative emissions during storage and refueling. Fuels that use a closed fueling system (CNG, electricity) do not incur this loss." storage costs, and ultimately mean lower fuel costs and emissions.

Fueling station or special service area. A special service area or fueling station will be required for all ATFs. As mentioned above, fleet vehicles are seen as ideal for the initial application of ATFs because they are usually centrally fueled and serviced; this can reduce the amount of initial investment required. All stations will require the use of land, buildings, and equipment for servicing and fueling.

CNG: For CNG, an initial decision must be made in estimating the cost of a station, and whether the system is to be a slow-fill or fast-fill (cascade) system. This will determine the number of tanks required for refueling and the necessary equipment. In all instances, requirements will include, in addition to the CNG fueling equipment, a compressor sufficient to pump the CNG up to approximately 3000 psi from the inlet pressure off the gas line. Because CNG refueling can be done outside, building structures may be kept to a minimum. For extreme weather conditions, inside refueling may be preferred. In this case, buildings will need to be adequately ventilated and meet federal, state and local regulations concerning the storage and dispensing of CNG in an enclosed shelter. In all cases, stations and structures must meet National Fire Protection Association (NFPA) and other applicable building codes regulating CNG.

Electricity: EVs can frequently be recharged where they are parked or garaged when not in use. This eliminates the need for a separate area for refueling. However, a service area is necessary for maintenance, such as watering the batteries and inspecting the battery packs on a regular basis. Furthermore, battery recharging should take place in a heated area in regions where cold weather is likely. An indoor charging area, if required, must be well-ventilated to accommodate the off-gassing of hydrogen during the final phase of charging.

Methanol: Because it is a liquid fuel, methanol requires a refueling station very similar to conventional gas stations. There are differences, however. Most important is the issue of underground storage tanks for methanol. The majority of underground tanks used to store petroleum fuel are not considered safe for the storage of methanol, due to its highly corrosive and toxic properties. New fiberglass tanks meet stricter codes, and are sufficient for storing methanol as well as gasoline. However, it should not be assumed automatica'ly that an existing gasoline station can be easily, and inexpensively, converted for methanol use. 


\section{"Fducation and training are critical componewts of a successful ATF program and should include everyone involved with the program, from managers and administrators to operators and mechanics."}

Generally the blending of fuels requires no adoitional equipment. Methanol is "splash-blended" with gasoline when used as an additive. If methanol is blended with gasoline before being stored at the station, a storage tank that meets the more stringent standards may not $b c$, necessary. If methanol is to be used as a neat ( $100 \%$ pure) or nearly-neat fuel, additional tanks may be required, in light of the lower energy density of methanol compared to gasoline.

Methanol is regarded as both explosive and toxic, and stations must conform to NFPA, state, and local codes regulating these substances. Furthermore, because of the tendency of methanol fumes to pool in low places, mechanics pits that are frequently used to service large vehicles (such as buses) in fleet stations can be hazardous. In some jurisdictions, this may necessitate building a new or special service area for methanol vehicles.

Fuel delivery system. Getting the fuel from the storage tank or power source, once fuel is available and the station is built, generally does not require much additional capital investment. However, each fuel has its own particular requirements. CNG requires an auxiliary compressor. EVs will need a heavy duty extension cord to connect the power outlet and the vehicle. Methanol may require special non-corrosive hoses, particularly when used as a neat fuel, and may require additional safety features such as gloves and goggles, for servicing.

Education and training. Education and training are critical components of a successful ATF program and should include everyone involved with the program, from managers and administrators to operators and mechanics. Initial training and education may include time and costs to cover:

- orientation lectures and seminars

- training courses in installation and repair of ATF systems $s^{6}$; or to have instructors travel to fleet service stations to provide instruction

- visits to other jurisdictions with similar ATF programs

- conferences or workshops related to ATFs.

These initial training and education costs are considered a capital investment in the infrastructure of an ATF program. They are one-time costs specifically incurred by the decision to use ATFs, separate from, and in addition to, ongoing training costs covered in the next section as operating costs.

\subsection{Operating Costs}

Operating costs are the expenses incurred periodically over the lifetime of a vehicle, including routine fueling, inspection, 
"The price of fuel delivered to the station and io the vehicle can vary significantly, depending not only on the type of fuel and its regional availability, but also on world market prices and manufacturing. The latter circumstances are beyond the control or, practically speaking, the estimation of local government project managers; however, the former are well within their scope." maintenance and repair. Many of these costs are identical to those of conventional petroleum fueled vehicles; however, some operating costs are particular to a specific alternative fuel type.

Vebicle costs. The operating costs associated with running a vehicle on a daily basis include the following expenses:

- fuel

- inspection and maintenance

- replacement parts.

Fuel. The price of fuel delivered to the station and to the vehicle can vary significantly, depending not only on the type of fuel and its regional availability, but also on world market prices and manufacturing. The latter circumstances are beyond the control or, practically speaking, the estimation of local government project managers; however, the former are well within their scope. Fuel price in all cases must include applicable local, state, and federal taxes, as well as any applicable motor fuel taxes. In the current regulatory environment, many exemptions to fuel taxes have been granted to alternative motor fuels.

Bulk, discount, or incentive rates are frequently available for local governments interested in converting part or all of their fleet to an ATF. The willingness of a utility or supplier to negotiate a special rate will depend in part on what the ratio is between its capacity, reserves, and peak demand. If the utility views the development of ATFs as an opportunity to expand their market or to utilize untapped capacity, it is likely to be supportive, both financially and technically, of a program that encourages the use of ATFs.

CNG: With CNG, there can be a significant difference between the price of the fuel delivered to the station and the price of the fuel delivered to the vehicle. The cost of CNG delivered to the vehicle depends on two factors: the choice of fueling system (slow or fast fill) and the inlet pressure of the gas in the pipeline. In all cases, an auxiliary compressor is required to increase the pressure from the pipeline to the 3000 psi held by a standard fuel cannister. This auxiliary compressor uses energy, usually electricity, to compress the natural gas. Depending on the number of vehicles being refueled daily, the amount of energy used by the compressor can add significantly to the cost of the fuel.

Electricity: With EVs, the price of the fuel delivered to the power station is the cost of the fuel; there is no additional expense. Because EVs are generally charged during off-peak hours (typically nighttime), the $\mathrm{kW}$ rate is usually lower than 
"If the utility views the development of ATFs as an opportunity to expand their market or to utilize untapped capacity, it is likely to be supportive, both financially and technically, of a program that encourages the use of ATFs."

during the day. Furthermore, the electric utility may be willing to grant a special incentive rate for using off-peak power, again reducing fuel costs. ${ }^{7}$ In some cases, the local electric utility has levied a demand charge on the fueling station, negating much of the economic advantage gained by switching fuels. ${ }^{8}$ In the near or middle term, electricity costs may be reduced by supplementing and/or supplying outlet power with solar electricity.

Methanol: Methanol generally must be purchased in bulk and delivered by truck, similar to petroleum fuel. Although currently there is an excess capacity for methanol production worldwide; regional availability may be limited. The only direct additional cost at the station for methanol fuel may be the expense to blend the fuel when it is used as an additive. However, in areas that have mandatory oxygenated fuel (oxyfuel) programs, blending does not seem to affect the cost of the fuel significantly.

Vebicle service and maintenance. Alternatively-fueled vehicles require periodic maintenance and inspection. With fuels such as CNG and methanol, which are used with an internal combustion engine, the maintenance and inspection procedures will be similar to those required by petroleum-fueled vehicles. EVs have a maintenance program that is suited to their particular motor and drive train. The inspection and maintenance procedures for different fuel types are covered in more depth in the UCETF "Guide to Alternatively-Fueled Vehicles." Procedures that could involve additional costs beyond those of conventionally-fueled vehicles are covered briefly below.

CNG: For CNG vehicles, all items added as part of the conversion kit, including tanks, hoses, and regulators, require periodic inspection as recommended by the manufacturer or conversion installer. The $\mathrm{CNG}$ cannisters require regular inspection and recertification in compliance with DOT regulations. Experience with CNG vehicles seems to indicate that despite the additional parts, they seem to require less maintenance overall than petroleum fueled vehicles, because CNG is a cleaner burning fuel.

Electricity: EVs, in addition to routine battery recharging, require periodic inspection of battery packs. This involves removing them from the vehicles, using a fork lift or similar equipment equipped with a load spreader. Battery packs must also be watered on a regular basis. Watering takes place after the batteries have been fully sharged; it is a relatively short (20 minute) process. The battery packs will have to be replaced during the life of the vehicle, with the frequency depending on many factors, including the mileage and duty cycle. Replacing the battery packs is relatively expensive, depending on the type of vehicle, the number of packs required, and the type of battery. All other parts of an EV - tires, lights, accessories, etc., - 
should be inspected and maintained as they would on a conventional vehicle. Again, evidence seems to indicate that, overall, EVs require less maintenance than a petroleum fueled vehicle.

Methanol: Vehicles using less than $15 \%$ methanol as a blend with gasoline do not generally require any additional inspection and maintenance other than what is recommended by the vehicle manufacturer. Vehicles converted to run on neat or nearneat methanol should have all aluminum and rubber parts checked regularly, as there has been corrosion of these materials associated with methario! fuel use. In OEM vehicles developed to run on neat methanol or as flex-fuel vehicles, this problem has been addressed by redesigning the vulnerable parts. Maintenance on these vehicles should be similar to conventionallyfueled vehicles.

Vehicle parts. Some special replacement parts will be required for alternatively-fueled vehicles, as mentioned above.

CNG: For CNG vehicles, these parts will include cannisters, hoses, pressure safety valves, regulators, reducers, and a mixer/ carburetor, all of which are installed as part of the conversion.

Electricity: Because EVs do not use an ICE, most parts associated with EVs will be unique. The primary special replacement part will be the battery packs. Other parts will include the controller, converter, and battery charger.

Methanol: Special parts for neat or near-neat methanol vehicles and flex-fuel vehicles include a fuel sensor and a cold start system. Although the mechanical parts of a methanol vehicle are the same as a gasoline vehicle, some special non-corrosive pieces may have to be used, as methanol corrodes terneplated (leadplated) fuel tanks, magnesium, copper, lead, zinc, aluminum, and some synthetic gaskets.

Infrastructure. Most of the infrastructure costs associated with operating expenses are fairly similar to those incurred by fleets operating on conventional fuels. These costs (and savings) include:

- program management/administration

- overhead

- registration, taxes

- insurance

- warranties

- retail fuel mark-up

- education and training.

There is a certain variation in these costs for ATFs. Program management and administration costs, for example, are predict- 
able for petroleum-fueled fleets. However, fleets using ATFs, particularly at the beginning of the program, are going to require more time and attention, more oversight and hands-on management than a conventionally-fueled fleet. While the management of an ATF fleet may not require special attention ever the long run, it will need a substantial investment of time and energy up front.

Overbead costs for ATFs will again be similar to those for petroleum-fueled vehicles. However, there may be increased overhead costs as a result of stocking special parts or operating a special service station that is used only by certain vehicles. In the long run, these additional costs may level out, and actually drop below the conventionally-fueled fleet costs as the number of vehicles using ATFs increases.

There seems to be little difference in the costs for taxes, titles, tags or registration for alternatively-fueled vehicles. Fees that are based on the weight of the vehicle may be slightly higher for these vehicles, because of the weight added by the extra fuel storage tanks (CNG, electricity, methanol) and the extra structural material (electricity) required. Future state and/or federal legislation may actually grant a reduction in these fees for ATFs as an incentive to their use. ${ }^{9}$

To date, most insurance companies have treated alternativelyfueled vehicles similarly to their conventionally-fueled counterparts. To the extent that altematively-fueled vehicles cost more than conventional vehicles, collision insurance on the vehicles will likely be higher. Some insurance may charge higher rates for fuels perceived to be more flammable or toxic (CNG, methanol), altho igh there is not clear evidence that these fuels are more hazardous than petroleum fuel. In the absence of standards within the insurance industry, rates may vary significantly from company to company. ${ }^{10}$

Insurance is also required for service stations. It is likely that the rates for underground storage tanks holding methanol will be significantly higher than those for petroleum fuels. Methanol has somewhat different propeities from petroleum. It generally is regarded as more toxic, an? is miscible in water; consequently, storage tank leaks are considered more serious. Because insurance rates for petroleum fuel storage tanks have recently been rising rapidly, the rates for methar,ol tanks may be very expensive. CNG refueling stations may also have higher insurance rates, again because of perceived safety issues.

Retail fuel mark-up may be avoided or diminished through the use of ATFs, as may relatively high motor fuel taxes. Both these savings can lower the daily operating cost and the total lifecycle 
cost of the vehicle by a substantial amount, as long as these special conditions exist.

Education and training is part of the expense for maintaining the workers to service anv fleet. Because ATFs require specialized skills, there will be additional training costs, over and above the conventionally-fueled costs, on a continuing tasis. Furthermore, employees with these specialized skills may need to be paid at a higher wage than those working on conventional vehicles.

\subsection{Lifecycle Costs}

Concept. The lifecycle cost of a vehicle, expressed as the rate of cost per mile, should be the critical value when evaluating the economic viability of any fuel. Particularly because many of the expenses associated with alternatively-fueled vehicles are difierent from conventional vehicles, the lifecycle cost is one way to make sense of the many variables.

"The lifecycle cost of a vehicle, expressed as the rate of cost per mile, should be the critical value when evaluating the economic viability of any fuel. Particularly because many of the expenses associated with alternatively. fueled vehicles are different from conventional vehicles, the lifecycle cost is one way to make sense of the many variables."
The most significant economic barrier to the development of ATFs is not the cost of the vehicle or the fuel; experience has demonstrated that these expenses can be brought within reasonable range of conventional vehicle costs. Attempts to calculate tixe lifecycle costs of ATFs raises a different issue for new technologies that cannot be circumvented: Who pays for the infrastructure costs, and how? This introduces the oft-cited "chicken and egg" dilemma of ATF development. The infrastructure will not develop without adequate demand, while such demand is unlikely to occur in the absence of an adequate infrastructure to suppori it.

The economic viability of ATFs in a particular jurisdiction will depend on the answer to that question; but there is no readily available solution. Many local governments have been able to work with a variety of partners, including the vehicle manufacturers, the fuel suppliers, industry associations and state and federal government to share the infrastructure costs. We have paid in the past, and continue to pay, these costs for petroleum and diesel fuels; it is important to remember that we must pay infrastructure costs at some point for all industries.

Methods. The basic method for determining lifecycle cost of a vehicle is to add together the total capital and operating expenses over the lifetime of the vehicle, subtract the salvage and recycling value, and divide by the total number of vehicle miles traveled. This calculation gives a straightforward cost per mile for any vehicle. 
"Alternatively-fueled vehicles are unusual in that they require higher front-end investment than conventional vehicles. These costs, sometimes a barrier to development and procurement of ATFs, can be justified economically by savings over the lifetime of the vehicle."
There are several real and theoretical problems with applying this formula to ATFs. As we have seen in discussing the direct costs in this section, many of the parameters needed to determine the lifecycle cost of alternative transportation fuels have not been firmly established. Quantities such as the life expectancy of the vehicle, the total amount of time required for maintenance, and the real fuel efficiency, can only be estimated based on incomplete data.

Because multiplying variables together magnifies their inaccuracies, a lifecycle cost estimate for ATFs may contain a high degree of uncertainty. Calculating the lifecycle cost for ATFs is not a futile exercise, however. If we do not have absolute figures for many of the variables, we have at least some fairly precise estimates. In many cases, cost modeling performed to determine lifecycle costs of ATFs includes both worst-case and best-case scenarios. ${ }^{11}$ Sensitivity analyses can also be performed that indicate which input data causes the greatest variation in the final answer.

Alternatively-fueled vehicles are unusual in that they require higher front-end investment than conventional vehicles. These costs, sometimes a barrier to development and procurement of ATFs, can be justified economically by savings over the lifetime of the vehicle. Even when the expense of ATFs only meet or slightly exceed those of petroleum fueled vehicles, there may be additional, external factors that tip the scales in favor of ATFs. ${ }^{12}$

Key variables. There are a number of variables used in calculating the lifecycle cost for ATFs that will differ significantly from those used for petroleum fuel. These key variables may include, but are not limited to:

- increased lifetime expectancy

- reduced maintenance - parts and labor

- value of recycled battery parks

- cosirimion on vehicles for forgone pollution control equipment

- fuel efficiency

- economies of scale available with OEM manufacturing.

Further research and use of ATFs will undoubtedly establish more reliable data to be used in lifecycle cost analysis; these, adjustments will improve the accuracy of these calculations. ${ }^{13}$ It is important to note that lifecycle costs for petroleum and diesel fuels, despite the extensive documentation of their costs, also are constantly being updated to improve accuracy. Uncertainty in the value of the variables should not be a barrier to using lifecycle cost analysis to determine the direct economic worth of ATFs. 


\section{Endnotes}

${ }^{1}$ OEM vehicles, especially for heavy-duty niche applications, may be available in the near future.

${ }^{2}$ Several jurisdictions have had difficulties using service providers who are not close by; routine adjustments of the vehicle conversion kit and troubleshooting become prohibitively expensive when travel time and costs are included. There should be a trained mechanic on staff who is familiar with the conversion process and can take care of minor problems.

${ }^{3}$ For example, areas without convenient access to gas pipelines are unlikely to choose $\mathrm{CNG}$ as an alternative fuel.

'Worldwide reserves of natural gas are extensive enough to be of minimal concern to a local government if the regional supply of natural gas is adequate.

${ }^{5}$ There is some concern about worldwide capacity to manufacture sufficient methanol in the near term if demand increases sharply.

${ }^{6}$ Hocking Technical College, in Nelsonville, Ohio, teaches a one week intensive class on the installation and servicing of CNG conversion kits for experienced mechanics. They are currently expanding their program to include other AVFs. Instruction in the installation and repair conversion kits may also be available from the kit provider. Instruction on the maintenance and repair of EVs and OEM vehicles should be available from the provider as well. Check with the provider in advance about the availability of instruction before purchasing.

${ }^{7}$ The use of off-peak power for peak-shaving and load spreading, as well as for the avoidance of capital investment in new power generating facilities, is of substantial concern to the electric utility industry.

${ }^{8}$ As reported by staff from the city of Albuquerque, NM, at the AVF Unit meeting in Ft. Lauderdale, October 16-17, 1989.

${ }^{9}$ For example, the state of Arizona recently passed legislation that reduces the registration fees for alternatively-fueled vehicles to provide an incentive for their use.

${ }^{10}$ New York City is currently working on a UCETF project examining insurance and leasing issues. This report should be available by December 1991.

${ }^{11}$ See models in Appendix A.

${ }^{12}$ This will be discussed more thoroughly in the section on indirect costs.

${ }^{13} \mathrm{An}$ alternative vehicle fuels information center and database is currently being established at the Solar Energy Research Institute (SERI) in Golden, Colorado. One of the purposes of the center will be to collect and standardize information related to alternat. ve fuels that is used for emissions impact and lifecycle costing. 


\subsection{Indirect Costs}

There are costs related to the use of any vehicle fuel, not directly involved with its purchase and operation, that are difficult to quantify. These indirect, or external costs (and savings), are not always tied to the economic bottom line of using ATFs; instead, they reflect the importance of other priorities in our society, such as health, safety, and the environment. In balancing the economic equation, it is frequently these less tangible indirect costs that tip the scales in the favor of ATFs.

Indirect (sometimes called "nonmarket") $\operatorname{costs}^{1}$ may be divided into three categories:

- regulatory

- institutional

- societal.

These categories reflect divergent priorities within different sectors that affect the choices between alternative and conventional fuels.

\subsection{Regulatory Costs}

Both state and federal governments affect the development and use of fuels through a complex system of unintentional, as well as deliberate, incentives and constraints. The motivations for these actions may differ, but they usually stem from one or more of three main "drivers":

- energy security

- air quality improvement (environmental)

- economic benefits. 
"The private utility industry has acknowledged that they have a responsibility to assist in developing the technology and infrastructure for the ATF industry if they want a market share in supplying the fuel for these vehicles. Private utilities, industry organizations, universities, and others in the private sector have joined with public organizations and the government in partnerships to achieve this end."
Federal programs. The federal government's approach to air quality problems has included a wide variety of actions, including penalties, constraints, incentives, mandates, and partnerships.

The best known set of federal regulations affecting the development of ATFs is the Clean Air Act. Cities that do not meet NAAQS established by this legislation face the loss of federal money for their transportation programs. Recent amendments to the Clean Air Act tighten these standards, and require the use of ATFs in some non-attainment cities. The details of the Clean Air Act are quite complex, and cannot be covered thoroughly here. ${ }^{2}$ However, all local government should be aware of the role of their transportation plan within the context of the State Implementation Plan required by the Clean Air Act.

In addition to the Clean Air Act, there are two other pieces of national legislation that will have a direct bearing on the use of ATFs by local governments. The first is legislation currently being considered by Congress that will implement the Bush Administration's National Energy Strategy (NES). The version of the NES that has been passed by the House contains some specific mandates for the accelerated development and use of ATFs beyond what is required by the Clean Air Act Amendments. Although the Senate has not yet passed this bill, it is very likely that the provisions related to ATFs will not be substantially changed.

Secondly, last fall Congress passed a comprehensive transportation bill known as the intermodal Surface Transportation Efficiency Act of 1991. The ISTEA represents a major reform of federal transportation policy compared to former laws, which emphasized highway construction. Instead, almost half of the traditional highways funds called for in the ISTEA can be used for other modes of transportation. The flexibility built into these allocations allows cities and counties to establish regional transportation strategies that include alternatives such as pedestrian routes, bicycle facilities and ATFs. The $\$ 6$ billion Congestion Mitigation and Air Quality Improvement Program will also provide an opportunity for local governments, particularly those in non-attainment areas, to obtain money for alternatively-fueled vehicles.

Other potential federal measures that could serve as a catalyst to the development of ATF programs on a state and local level include:

- mandates for the production of alternatively-fueled vehicles by manufacturers

- partnerships with local governments, national labs, and private sector interests 
- fuel subsidies to encourage the use of alternative fuels

- further penalties against regions that do not bring their air quality or their fleet vehicles up to standards by the established deadlines

- taxes or fines on fuels or vehicles that do not meet revised standards

- revising federal regulations that unnecessarily constrain the use (transportation, storage, dispensing) of ATFs.

It appears that the development and use of ATFs will have a substantial role as part of a comprehensive federal strategy for improving air quality. If the federal government demonstrates its commitment to the use of ATFs, support from other sectors is likely to follow suit.

State and local programs. Many cities, counties, and states with serious pollution problems have already begun to develop ATF programs as one approach to improving air quality. The most common regulatory tools used on a state and local level to encourage ATF use are regulatory mandates, penalties, and incentives.

Legislative mandates requiring the use of oxyfuel blends have been used by a number of cities and regions (e.g. Phoenix, Denver, Albuquerque) to effect an immediate impact on serious air quality problems. Legislative mandates may also be used to establish a cohesive and consistent long term strategy for resolving air quality problems. California, with the South Coast Air Quality Management District (SCAQMD), is well ahead of the rest of the country is taking this approach. They have developed a regional plan that aggressively addresses the air quality problem through many different avenues, including the use of a variety of ATFs. In this case, part of the legislative mandate involved making public funds available to support this plan. More recently, Texas has promulgated some far-reaching legislation that will also have a significant impact on the ATF market.

The private utility industry has acknowledged that they have a responsibility to assist in developing the technology and infrastructure for the ATF industry if they want a market share in supplying the fuel for these vehicles. Private utilities, industry organizations, universities, and others in the private sector have joined with public organizations and the government in partnerships to achieve this end. These private sector businesses have contributed financial, technical, and in-kind assistance to support the development of ATFs.

More recently, manufacturers have shown an increasing interest in alternatively-fueled vehicles, partly as a result of the intent of National Energy Plan and the Clean Air Act Amendments. The 
recent agreement between GM Trucks, the Texas Land Commission, and 10 leading natural gas utilities for GM to produce over 1,000 light-duty trucks that will operate on CNG is one example of how partnerships between the public and private sector can establish a significant market for the manufacturers.

Penalties may be levied against vehicles that exceed fuel efficiency and emissions standards set by state and local authorities. In the case of the SCAQMD, regional emission standards are more stringent than the NAAQS (National Ambient Air Quality Standards) established by federal regulation. Increasingly stricter standards will require manufacturers of fleet vehicles, in particular, to either find a way to run much cleaner on petroleum fuel or switch to ATFs.

\subsection{Institutional Costs}

"It appears that the Institutional costs reflect the existing structure of our private and public sector development policies. As our policies evolve in response to an increasing awareness of our limited economic and environmental resources, the associated costs also change. There are three primary institutional costs involved with ATFs: part of a comprehensive federal strategy for improving air quality. If the federal government demonstrates its commitment to the use of ATFs, support from other sectors is likely to follow suit."

- energy security

- economic development

- labor.

Energy security. Energy security became a significant public issue in the United States during the energy shortage of the 1970s.

The subsequent drop in oil prices during the 1980s reduced the public concern about our dependence on foreign fuel supplies in the near term, but in long-term planning our vulnerability to disruptions in our fuel supply remains critical. Because approximately $63 \%$ of domestic and imported petroleum oil is used in the transportation sector ${ }^{3}$, alternative fuels have the potential to alleviate some of our reliance on imported fuels.

Most people in the industry agree that it is unlikely that one single ATF will completely dominate the developing market. Diversification of fuel types can reduce our reliance on particular regions of the world that produce the majority of a specific fuel, such as petroleum in the Middle East. Many of our future vehicle fuels - including natural gas, methanol, ethanol, electricity, and hydrogen - are available to us within U.S. borders, or are located in more widely scattered areas throughout the world. Some ATFs can be developed as renewable fuel resources, further reducing our need for foreign imports, and mitigating some of the concern about future energy sources. 
Econcmic development. Economic development can be tied to the issue of energy security in a number of ways. Dependence on foreign fuel moves funds out of the U.S. economy and aggravates our trade imbalance; this can have a direct bearing on the amount of money available for investment in development on a local level. The direct and indirect costs related to importing foreign petroleum include, but are not limited to:

- loss of employment due to overseas production of fuel

- transportation and delivery of fuels over long distances

- military protection of foreign fuel sources (e.g., maintaining a naval fleet in the Middle East)

- maintenance and protection of strategic petroleum reserves. ${ }^{4}$

Viable replacements for petroleum fuels, such as ATFs, can help minimize or eliminate these costs.

Growth and economic development of cities, townships and counties depends on a number of factors, including relatively cheap and stable energy costs. ATFs can contribute to local development by providing transportation run on cleaner fuels that meet these criteria. Furthermore, by reducing the need for petroleum fuel for transportation, more petroleum is available for use in other areas.

Labor. Union and other labor agreements between workers and management generally have not anticipated the implementation of ATFs. Although ATFs are still a neophyte technology, issues have already begun to emerge with workers, particularly those with union contracts. For example, a mechanic maj be precluded from working on an alternatively-fueled vehicle if it is not included in the union contract. The union may require strict additional safety precautions for employees working with these fuels (even though they are not necessarily more dangerous), because their relative safety and toxicity is not as well documented and is less accepted than petroleum fuels.

Training and skill levels may also be important issues with ATFs. Special skills are required for workers installing the conversion kits and servicing the vehicles, and possibly for workers operating the vehicles and managing the fleets as well. They will need training to acquire these skills; consequently, these employees may have to be rated at a higher level and/or paid at a higher rate than their counterparts who work on conventional vehicles. Finally, although there are relatively few workers experienced with ATFs, there may be problems with bringing a non-union specialist in to work on fleet vehicles, or to train union workers. 
All of these issues may involve renegotiating with employees or unions to accommodate changes in the transportation fleet. A higher level of training and skills will almost certainly mean higher costs for labor, either directly or indirectly.

\subsection{Societal Costs}

We are only beginning to understand the dramatic impact that the use of petroleum oil and other fuels has had on human and environmental health. It is even more difficult to estimate the economic loss resulting from continuing air pollution. The SCAQMD and others have begun attempts to quantify these costs - assigning monetary values for health problems such as migraine headaches and asthma attacks, estimating lost productivity in the workplace - and calculating the cost to repair at least the worst of the potentially irreversible damage to our environment.

As the demand for an accounting and rectification of these damages increases, expenses to repair the damage are becoming a significant factor in the cost of the fuels we presently use. Severe air quality problems violate what we believe is our right to a certain quality of life - good health, clean air, and a sound environment - that has become a priority for many people. ATFs, by significantly reducing the amount of harmful vehicle emissions, have a near-term and long-term potential to mitigate some of the monetary and quality of life costs of air pollution.

Human health costs. Air pollution's contribution to human ailments is a complex problem. Clearly, poor air quality aggravates and may create a wide number of health problems, including asthma, emphysema, allergy sensitivities, heart conditions and migraine headaches. In addition to the discomfort or pain caused to an individual, there is a direct economic loss in the workplace reflected in the amount of sick leave required and a decrease in productivity.

Poor air quality can also have a direct effect on the cost of medical treatment, resulting from intermittent and chronic health care problems. These costs are initially paid by the government, employers, and health insurance companies. Eventually these costs are passed back to the citizen in one form or another: as taxes, reduced coverage, increased health care costs.

Environmental costs. Air pollution has a wide-ranging effect on the health of our environment. In weighing the economic benefits of ATFs, the cost to repair unacceptable damage to our environment caused by the contributions of mobile source 
"We must be careful that with the use of new fuels, we do not increase the emissions of currently unregulated pollutants that may cause equally severe or worse air quality problems in the future. With foresight, this risk can be minimized or eliminated." emissions to air pollution must be considered. Problems such as the destruction of the ozone layer, greenhouse warming, acid rain and smog, along with secondary pollution of our water and food by air toxins, will require ever larger commitments of both time and money in the coming years on a local, national, and international scale.

Money invested in finding and developing solutions to our pollution problems, such as ATFs, may save us from overwhelming costs in the long run. Furthermore, if we do not take aggressive steps toward improving our air quality, it is possible that the damage to our environment will be irreversible. There is, however, a caveat with ATFs. We must be careful that with the use of new fuels, we do not increase the emissions of currently unregulated pollutants that may cause equally severe or worse air quality problems in the future. With foresight, this risk can be minimized or eliminated.

There are environmental issues stemming from the production of all fuels are frequently overlooked when evaluating the emissions impact. Therefore, a fuel that causes considerable pollution during its manufacture may not have the overall air quality benefit it appears to.

CNG: CNG is perhaps the fuel least likely to have these concomitant production problems; in fact, there is great potential to save natural gas that is currently vented, flared, or reinjected during the drilling for petroleum and other fuels. However, there is for CNG the basic machinery and energy needed to extricate the fuel from its source.

Electricity: The overall picture for electricity generation is very sensitive to the type of fuel used at the power plant. For example, the use of high sulfur coal to produce electricity could negate virtually all of the advantages gained by the switch to electric vehicles. On the other hand, the use of photovoltaic cells (pvs) to recharge an electric vehicle could result in a renewable fuel that is virtually free of emissions.

Methanol: Methanol has manufacturing costs that depend on its source. Currently, most methanol is made from CNG through a somewhat complex process. The manufacture of methanol requires consumption of approximately $30-40 \%$ of the energy inherent in the fuel, raising the issue of efficient use of world resources for fuel production. 
Lastly, we must accept the fact that a significant increase in the amount of fuels being transported, regardless of precautions, will cause a related rise in the number of spills and accidents. There are costs associated with the prevention of these accidents, the losses incurred, and the efforts necessary to rectify damage.

\section{Endnotes}

${ }^{2}$ Cost is a difficult word to use in this context, because it connotes a monetary amount that is not applicable to many of the subjects discussed in this section. Cost in this case could mean more closely, value or worth. How these indirect costs are determined reflects the evolving values and priorities of local governments and their constituents.

${ }^{2}$ A good source for information on the details and implications of the Clean Air Act for local governments is Bob Yunkhe at the Environmental Defense Fund in Denver, Colorado.

${ }^{3}$ According to the American Petroleum Institute, January, 1990.

${ }^{4}$ The FY 1991 Budget requests $\$ 424$ million for maintaining the Strategic Petroleum Reserves. 


\subsection{Cost Comparisons}

Comparisons among ATFs, and between ATFs and petroleum fuels, are not straightforward. There are many inherent difficulties, ranging from incomplete information about the lifecycle costs of ATFs, to the prejudicial use of petroleum costs as the norm against which we cvaluate other fuels. ATF technology is also a rapidly changing field, and cost estimates which are accurate today may change substantially in one or more years. This is true for petroleum-fueled vehicles as well, but to a lesser degree. This section will discuss some of the issues involved with making these comparisons.

\subsection{Lifecycle Costs}

As mentioned earlier, the complete data necessary to calculate the actual lifecycle costs of alternatively-fueled vehicles is not yet available. Although we have good estimates for many of the values, they have not all been verified by practical experience. Evidence from research, modeling, and demonstration projects to date indicates that lifecycle costs of alternatively-fueled vehicles are likely to be comparable to conventional vehicles in the worst-case scenario. The best-case scenario for lifecycle costs would include alternatively-fueled vehicles that in take advantage of the economies of scale in mass production. In this scenario, lifecycle costs would be substantially lower for most alternatively-fuelcd vehicles.

Practically speaking, production and operation of alternativelyfueled vehicles is likely to fall somewhere between these two extremes. The rate of market penetration for alternatively-fueled 
"Nonmarket drivers are the primary incentive for federal policy, and the primary justification for federal intervention in the transportation market." vehicles will depend on a large number of factors, many of them external to market demands.

\subsection{Balancing the Costs}

Assessing the economic and practical viability of ATFs requires weighing and combining the direct and indirect costs associated with these fuels. State and local governments, private interests, and the public all have different perceptions and priorities regarding the balance of these costs.

Government priorities. Nonmarket drivers are the primary incentive for federal policy, and the primary justification for federal intervention in the transportation market. As the result of a variety of pressures, the federal government is in the process of establishing a national clean air policy and a national energy strategy. The Bush Aciministration's approarin to federal government involvement emphasizes market driven: incentives for the public and private sectors to achieve these goals.

Federal government intervention on the side of ATFs can have both positive and negative effects, as demonstrated in a number of countries. New Zealand, Brazil, and Canada, in particular, began the use of ATFs primarily as a response to government mandates, incentives, and subsidies. In New Zealand, and to a lesser extent in Canada, widespread use of ATFs did not develop, despite federal government intervention. In Brazil, the program succeeded only as long as there was strong direct government intervention. These programs faltered for a variety of reasons, but these experience ckemplify the impact direct institutional support can have $O=\ldots$ development.

When institutional momentum brings in partners, generates interest, and increases funding sources, it is helpful. When institutional momentum reduces flexibility and constrains development of a program so that it cannot respond to market demands, it is harmful. The potential for a significant push from the federal government toward ATFs may generate a lot of money and stimulate the development of ATFs. However, if the federal government policy has a predisposition toward one particular fuel or fuel program, it may cause serious setbacks to the development of the ATF industry.

The best place for government intervention may be in use removal of barriers and restrictions to the use of A'l lis, coupled with incentives to increase the competitiveness of ATFs with conventional fuels, as part of a wider effort aimed at developing the infrastructure required for these fuels. This would help solve the "chicken and egg" dilemma that the ATF industry faces, 
while at the same time providing a level playing field for developing different fuels in response to market demand.

Private industry concerns. The primary motivation for private industry interest in the development of ATFs is economic. Consequently, their concerns focus on how much investment will be needed, and their return on this investment. For most utilities, expansion into ATFs represents a new market with considerable economic potential. Private utilities and industry associations have generally been very supportive of ATF programs, and in a number of cases have taken the lead in their development and marketing.

In a rapid growth industry, such as ATFs, where significant technological improvements occur with a certain frequency, utilities can be reluctant to invest in an expensive infrastructure or technology that may be obsolete in a relatively short anrount of time. It is also difficult for the private sector $m$ invest in ATFs without knowing how the marker is going to develo'? and in particular, which fuel or fuels are going to dcminate the market.

Commitment by fideral and state and local governments to ATFs is one way to help overcome some of these obstacles. A

"When institutional momentum brings in partners, generates interest, and increases funding sources, it is helpfu!. When institutional momentum reduces flexibility and constrains development of a program so that it cannot respond to market demands, it is harmful." long term federal policy aimed at encouraging the development of ATFs will assuage at least sorne of the concerns that the private sector has about investing '. bstantial amounts of money in an uncertain market.

Pubiic coricerns. The public's view of the balance between internal and external costs hinges largety on its collective values and its perception of the risks involved. There is a clear movement toward serious concern about our environment, on grassroois, national, and international leveis. If ATFs are presented as one way to address this concern, without significant cost increases or risks to the consumer, they are lit.ely to be successful. Public support of policies and legislation encouraging the use of ATFs is a significant factor, because sales of alternatively-fueled vehicles to individual consumers is not seen as a large part of the mar. ket; initial use of ATFs will be predominantly in public and private fleets for reasons discussed in other sections.

\subsection{Comparisons with Petroleum Fuels}

Tor practical reasons, petroleum fuels are usually used as the standard by which ATFs are judged. However, in the long run this must change because it is not realistic to use petioleum fuel costs as the baseline against which to compare estimated or real ATF costs. There are several reasons, from an economic perspec- 
"A long term federal policy aimed at encouraging the development of ATFs will assuage at least some of the concerns that the private secto: has about investing substantial amounts of money in an uncertain market." tive, why ATFs should not be evaluated only within the context of petroleum fuels.

First, comparing the petroleum fuel industry to the ATF industry is like comparing apples and oranges; it makes no sense because they are not the same. As discussed in other sections, there are many infrastructure and indirect costs associated with the development of the neophyte ATF industries that elevate the initial costs of these fuels. These costs will probably be absorbed by many different sectors of our society: federal and local governments, vehicle manufacturers, fuel suppliers, and the private citizen. Petrcleum fuels are a mature industry, and have a virtual monopoly on the transportation sector; consequently any change in the status quo is going to require considerable financial investment.

Secondly, modeling and other cost estimates have usually tied the cost of ATFs directly to the cost of petroleum fuels. It has been assumed that there is little or no incentive to develop and use ATFs unless the cost of oil becomes prohibitively expensive, or the cost of the alternative fuel can be somehow brought down to the break even price with petroleum. In fact, there are many other direct and indirect economic justifications for pursuing ATFs, independent of petroleum fuel prices.

Lastly, we discussed in other sections the real costs of vehicle fuels, including direct economic costs, and inclir at costs such as protection of fuel sources and damage to the environment. It is important to understand that we do not currently pay these indirect costs for petroleum fuels at the fuel pump. These prices are artificially low, because we pay for the indirect costs generated by the use of petroleum fuel in other ways - through state and federal taxes, through the trade deficit, and through the budget deficit. 


\subsection{Financial Decisions}

"Different fuels are suited to speciñic uses in fleet applications, defined by duty cycle and vehicle type. These niches will be an important factor in the concurrent development of different ATF technologies."
This section provides a discussion of the factors that will have an impact on the overall financial scenario of ATFs. Neither ATF technology nor the ATF industry is identical to that of conventional petroleum fuels. If ATFs are to be economically competitive, changes need to occur in many of the standard ways vehicles are evaluated and purchased. Motivated by the "drivers" discussed in earlier sections, the catalyst for these changes will be the priorities established by the federal, state and local governments, their constituencies, and the private sector. The issues raised in this section will have an impact on how ATF use develops and what the associated costs will be.

\subsection{Alternative Fuels and Duty Cycles}

The decision to use a particular fuel will be based in part on specific requirements such as the distance a vehicle must travel per day, minimum speed and drivability standards, refueling opportunities, flexibility in schedule, etc. Different fuels are suited to specific uses in fleet applications, defined by duty cycle and vehicle type. These niches will be an important factor in the concurrent development of different ATF technologies.

The likelihood that no one ATF will completely dominate the vehicle fuels market has substantial implications for economic issues and for the development of the ATF industry as a whole. Some of the factors that will be affected by fuel choice include:

- rate of market penetration

- rate and type of infrastructure development

- implications of fuel diversification. 

"The uncertainty introduced
by potential variables such as
increased competition,
instability of fuel supplies, and
the market response to supply
and demand of fuels, may
cause significant changes not
only in the cost of fuels, but
also in the way in which the
vehicle fuels market operates."
These issues are all closely related, and to a certain extent, symbiotic.

The rate of market penetration will have an impact on the cost of alternatively-fueled vehicles, particularly with respect to the advantages of the economies of scale associated with OEM vehicles. The totai cost difference between specially manufactured or converted vehicles and OEM vehicles are likely to be substantial. If several fuels are vying for position within the vehicle fuels market, this means that a single fuel is less likely to achieve a rapid rate of market penetration.

Slower market penetration for each fuel also means slower development of accompanying services that make up the infrastructure that supports each fuel. This can affect everything from the number of fueling stations to the availability of parts and qualified mechanics to service the vehicles. The development of several distinct fuel infrastructures simultaneously may strain the limited financial resources available for this type of investment.

The loss of the petroleum monopoly on the vehicle fuels market, foreshadowed by the development of alternative transportation fuels, has far-reaching implications. The uncertainty introduced by potential variables such as increased competition, instability of fuel supplies, and the market response to supply and demand of fuels, may cause significant changes not only in the cost of fuels, but also in the way in which the vehicle fuels market operates.

Choices about appropriate fuels for niche applications will aiso be a decisive factor in creating options for financing alternatively-fueled vehicles and the infrasiructure to support them. However, it is also an opportunity for fleet managers and policy decision-makers to choose the most energy-efficient and cleanest vehicles and fuels to meet their needs.

\subsection{Vehicle Options}

Traditional budget and procurement procedures frequently present a barrier to the use of ATFs at a local government level. Many of these procedures were established to accommodate petroleum fueled vehicles as the norm, and are not flexible enough to incorporate the special financing requirements of alternatively-fueled vehicles. The implementation of successful ATF programs will require change or revision of budget and procurement procedures in order to make vehicles financially accessible. Some of the financing options for vehicle procurement include:

- purchase through traditional and alternative financing options

- leasing and leasing-to-buy 
"The implementation of successful ATF programs will require change or revision of

budget and procurement procedures in order to make vehicles financially accessible."
- joint financing programs with government, utilities, industry, and other private sector partners

- co-operative agreements, including donations for in-kind assistance

- grants or donations from public or private organizations

- "found" money resulting from law suit awards, oil overcharge funds, etc.

\subsection{Infrastructure Options}

Infrastructure costs represent one of the most significant barriers to the widespread use of ATFs. This problem is compounded by the fact that it is not clear where the responsibility for developing the necessary infrastructure belongs. The federal government, through Clean Air Act legislation, has provided both a catalyst and a framework within which this infrastructure can develop. However, there is not likely to be one group that is willing to assume these entire costs. Rather, it is likely that this infrastructure will be funded on a piecemeal basis, depending on local or regional circumstances. Participants in the building of this infrastructure may include:

- utilities

- industry associations

- government (local, state, and federal)

- vehicle manufacturers

- private organizations

- public and private investors

- public interest groups.

Establishing the infrastructure is likely to be a step-by-step process, incorporating a growing number of participants from different sectors as the use of ATFs spreads. For reasons mentioned earlier, ATF use is currently targeted at public and private fleets. This will hold down infrastructure costs until the use of ATFs grows and can support further investment. 


\subsection{Conclusion}

It is the crucial role of city and county governments to evaluate the true costs of all transportation fuels, and decide which fuels best meet their overall needs. Increasingly, local governments will have to evaluate their decisions within the larger context of national and international concerns, and consider the impact of these choices on our standard of living, the environment, and energy sources available for the future. Actions taken by national or international agencies may seem remote to local governments, but cities and counties are the most important link between the decisions of policy makers and their effective implementation.

\subsection{International Considerations}

In June of 1992, the United Nations is sponsoring the largest international conference ever to be held. The Conference on Environment and Development, nicknamed the "Earth Summit", is expected to pass international conventions on several issues, including one on global climate change. The global climate change convention will likely include a number of recommendations related to transportation, including the reduction of mobile source emissions that contribute to the destruction of the ozone layer. Although the conventions will be written, debated, and passed by policy delegates from over 100 nations, conference organizers recognize that it will be at the regional and local government level in each of the signatory countries that these policies will be implemented. The effectiveness of these conventions will depend on the efforts of city and county staff to translate the conference agreements into action. 
The International Council on Local Environmental Initiatives (ICLEI) is coordinating a long-range urban $\mathrm{CO}_{2}$ mitigation project. Twelve cities and urban counties, five in North America and six in Europe, are participating in a 10 year project to develop and implement effective strategies for reducing $\mathrm{CO}_{2}$ in urban areas. Of the jurisdictions in the United States that are part of this program ${ }^{1}$, all will be looking to reduce mobile source emissions as one important component in their overall strategy to improve air quality and decrease climate change emissions.

\subsection{National Considerations}

In addition to activities on the international level, the United States has in place, or is considering, four major pieces of federal legislation that will dramatically affect the transportation policies and planning of local governments, and, in particular, the use of alternative vehicle fuels.

First is the Alternative Motor Fuels Act (AMFA) of 1988 (Public Law 100-494) which is intended to encourage the development and widespread use of methanol, ethanol, and natural gas as transportation fuels by consumers, and encourage the production of methanol, ethanol, and natural gas powered motor vehicles. To meet these objectives, the AMFA provides vehicle manufacturers with incentives to produce alternative fuel vehicles. The law also requires the demonstration and testing of alternative fuels in a variety of vehicles and calls for several studies to further understand alternative fuels. Government agencies participating in the program include U.S. Department of Energy, the General Services Administration, the U.S. Department of Transportation, and the U.S. Environmental Protection Agency.

Second is the Clean Air Act Amendments of 1990, which contains broad legislation that will affect most urban areas. The Act requires comprehensive and coordinated transportation planning on the local, regional, and state levels. It also mandates that fleets of vehicles in non-attainment areas convert to cleaner burning fuels as part of the effort to bring urban air quality within compliance of the NAAQS. The motivation behind the Clean Air Act is environmental: urban populations must have clean air to breathe. It is important to point out that while the Clean Air Act contains much important regular ion, it contains no funding to achieve these goals.

The third major effort underway in Congress is the implementation of the National Energy Strategy (NES) developed by the USDOE and the Bush Administration. The House has passed a 
version of the NES that is still being considered by the Senate. Although the final language is not certain at this time, it is very likely that the bill will include strong support for one or more types of ATFs.

D. Iring the reauthorization of the Surface Transportation Act, there was extensive debate about what our national transportation policies should be, and at what levels these priorities should be determined. The final legislation, the Intermodal Surface Transportation Efficiency Act of 1991 (ISTEA), provides an increased amount of flexibility in funding and allows local governments to become key players in this discretionary spending. Rather than continue with "business as usual," the ISTEA encourages local governments to consider new and different solutions to transportation problems, and at the same time recognizes the link between transportation and other issues, such as air quality. In order to take advantage of this opportunity, however, local governments will have to become aggressively involved in the transportation planning and implementation process for their region and state.

\subsection{Local Considerations}

The recent interest in alternative transportation fuels has been a grassroots movement, built from the ground up through city, county, and state governments. Ahead of any federal mandates or initiatives, local governments have led the way to cleaner fuels, through applied ATF technology, innovative policies, and model legislation; and it is likely that local governments will continue to lead the way for federal agencies. Therefore, it is critical that local governments recognize the impact that they can have.

The importance of the role of local governments as "leaders by example" cannot be overstated. Demonstration projects of 5,10 and 20 alternatively-fueled vehicles can generate important and much needed information. However, it will not be until thousands and hundreds of thousands of vehicles are running on ATFs that we will see any significant impact on air quality, energy security, or cost reduction. Public fleets are the optimal way to begin to establish the necessary infrastructure that will lead us to a future where ATFs are the norm in public and private fleets, and even for individual citizens.

Experience has taught that unless a fuel can be cost-competitive with gasoline or diesel, no other driver is sufficient on its own merit to guarantee the successful and widesprcad use of ATFs. In cases such as New Zealand and Brazil, where strong federal regulation encouraged the use of ATFs, the program declined precipitously when government support was withdrawn. If the 
use of ATFs in the U.S. is to be successful in the long run, these fuels will have to be cost-competitive with gasoline and diesel.

For this reason, it is imperative that local governments examine the economic costs of ATFs. But they must do so in a way that considers the entire range of economic implications, both internal and external. The costs associated with external factors that have been discussed in this paper eventually are borne by the constituency that local governments serve directly: the citizen. Costs that are not paid directly at the fueling station are paid indirectly through higher federal, state, and local taxes, and other means.

Local governments are not being asked to take on this burden alone. The strength of the effort to put ATFs into broad commercial use will come from federal, state, and local governments working with the private sector to everyone's benefit. Each will need to invest experience, technical expertise and capital in order to build the infrastructure to support these fuels. Success will be when there are many fuel choices, but none are considered "alternative."

\section{Endnote}

${ }^{1}$ U.S. jurisdictions participating in the ICLEI $\mathrm{CO}_{2}$ mitigation project are Dade County (FL), Minneapolis (MN), Portland (OR), and San Jose (CA). Toronto, Canada will be the fifth North American city in the program. 


\section{Appendix A AVFCAP Management Committee}

AVF Unit Co-Managers

Creighton Lederer

Director

Buildings \& Safety Engineering

Detroit, MI
Chuck Clinton

Director

D.C. Energy Office

Washington, D.C.

AVF Management Committee

Paul Brown

Stan Bull

Executive Director

Director

EV Association of the Americas

Solar Fuels Research

Washington, D.C.

Division

National Renewable

Energy Laboratory

Golden, CO

Cliff Hayden

Alternative Fuels Specialist

Continental Management

Associates, Ltd.

Everett, WA
Helen Petrauskas

Vice-President

Environmental and Safety

Engineering

Ford Motor Company

Dearborn, MI 
Jeff Seisler

Executive Director

Natural Gas Vehicle Coalition

1515 Wilson Blvd., Suite 1030

Arlington, VA
Jack Werner

Business Director

Public Technology, Inc.

1301 Pennsylvania Ave., NW

Washington, D.C. 


\section{Appendix B List of Related UCETF Reports}

"Alternative Transportation Fuels: Infrastructure Issues" New York, NY; DG/89-327

"Alternative Vehicle Fuels: A Dernonstration Project" Albuquerque, NM; DG/90-316

"An Alternative Fuels Evaluation System for Fleet Vehicles" Denver, CO; DG/89-325

"Analysis of Programmatic Fleet Converstion to Ethanol Blends" Phoenix, AZ; DG/89-330

"A Regulatory Framework for Alternative Fuels and Transportation Management Services" Denver, CO; DG/90-318

"Fleet Assessment for Opportunities to Effectively Deploy LightDuty AVS"

Detroit, MI; DG/89-326

These reports are available from PTI, Publications Department; call toll free 1-800-852-4934. 


\section{Appendix C AVF Economic Evaluation Scenarios}

1. "Preliminary Analysis of Vehicle, Fuel Distribution, and Fuel Volume/Price Requirements for Clean Air Act 'Clean Fuels' Program." 


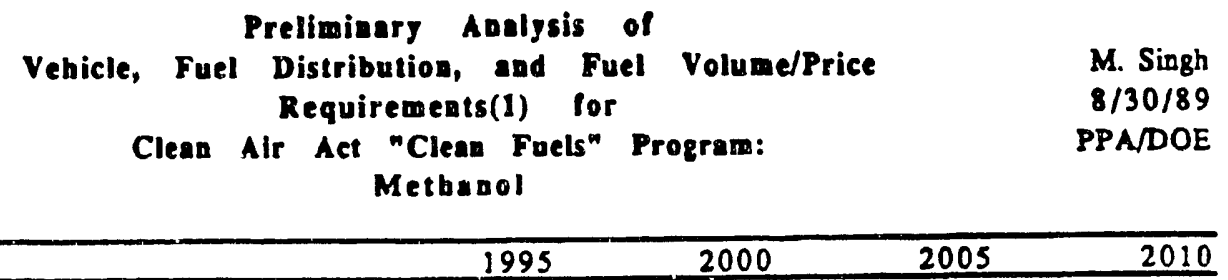

I. Fuel Volumes(2) (Billior gal/year)

(in Ozone Nonsttainment Areas)

Methanol Used(3)

Gasoline Displaced(4)

Gasoline Used

II. Potential Fuel Price Changes

Methanol Subsidy

e Se/gal. Methanol(5) (Million)

Gasoline Price Increase Required

to Support 5\&/gal. Subsidy(6)

$\begin{array}{rrrr}0.5 & 3.7 & 5.9 & 7.1 \\ 0.2 & 1.8 & 2.9 & 3.6 \\ 23.2 & 24.2 & 25.5 & 26.7\end{array}$

III. Methanol Production Plonts (Required Number)

2,500 MT/D Plant Size

of $10,000 \mathrm{MT} / \mathrm{D}$ Plant Size

IV. Refueling Outlets(8)

In Ozone Non-Atlainmeat Aseas to

Serve Flexible Fuel Vehicles

v. Vehicles

Annual Sales(10) $\begin{array}{llll}\$ 23 & \$ 184 & \$ 295 & \$ 357\end{array}$

$0.1 c / g a l . \quad 0.8 c / g a l . \quad 1.2 \& / g^{2} . \quad 1.3 \& / g a l$.

Cars

680,000 Light Trucks

320,000

QM

Ford

Chrysler

European

Asian

230.000

140.000

70,000

40,000

200,000

\section{aM}

Ford

Chrysler

Otbers

110,000

100,000

70,000

40,000

Total Methanol Vehicles in Use(11) (Million)

5.2

$1.1 \%$

$10.7 \%$

9.5

12.6

\% of LDVs in Ozone Nonattainment Areas

vI. Capital Costs - Cumulative (Billion)

2.500 MT/D Methanol Plant(12)

or 10,000 MT/D Mcthanol Plant

Refucling Outlets(13)

Vehicles (14)

$\begin{array}{cccc}\text { S0.54-\$0.74 } & \$ 3.78 . \$ 5.18 & \$ 5.94-\$ 8.14 & \$ 7.29-\$ 9.99 \\ \$ 0.68-\$ 0.92 & \$ 2.72-\$ 3.68 & \$ 4.08-\$ 5.52 & \$ 4.76-\$ 6.44 \\ \$ 0.08 & \$ 0.64 & \$ 1.02 & \$ 1.24 \\ \text { S0.14 } & \$ 1.44 & \$ 2.82 & \$ 4.19\end{array}$

See Explanatory Notes Allached 


\section{Explanatory Notes: Methanol}

1. All figures based on the proposal for sales of .5 million "clean fuel" light duty vehicles in 1995,.75 million in 1996 and 1.0 million each year thereafter, in nine worst ozone non-attairment areas. While the President's program only proposes sales through 2004, It is expected that sales of 1 mallion "clean fuel" vehicles will continue in subseguent years. The nine worst ozone non-attainment areas have a population of 57 million people or 238 of U.S. population (Source: EPA Offlce of Mobile Sources). Vehicle populations and fuel use in affected areas assumed equal to 238 of U.S. total. All figures are preliminary and subject to change.

2. All tuel volumes taken from DOE Motor Fuel Consumption (MFC) Model 14th Periodical Report Base Case as modified by methanol vehicle sales schedule, reported in BUSHRUN 1. DAT. Vehicles assumed to use $M-85$ with an M.85/gasoline mpg ratlo of 1.74 ..e.. equal BTU fuel efficiency.

3. 758 utilization of methanol assumed, meaning that 258 of the time the fuel flexible methanol vehicles are outside ozone non-attainment area and use gasoline.

4. Calculated to account for the 815 gasoline (by volume) in $M-85$.

5. Actual subsidy required to equalize methanol and gasoline prices depends on factors that are can not be accurately estimated at this time. $5 \mathrm{c} / \mathrm{gal}$ is used here as an example. If greater or lesser subsidy is required, these figures can be adjusted in direct proportion to the per gallon subsidy.

6. Assumes only gasoline sold in ozone non-attainment areas bears the price increase or tax.

7. 908 capacity utilization assumed on methanol plant of the stated nominal capacity.

8. Based on each outlet dispensing 30,000 gal/month $M-85$ or 100,000 gal/months of all products. By 2010, about 508 of all outlets in non-attainment areas would have nethanol available.

9. If dedicated vehicles are mandated, then additional outlets will be required (1) initially in ozone areas and (2) outside the urban areas to allow dedicated vehicles to travel freely. 108 is the minimum fraction that studies (on diesel vehicle owners) have shown will satisfy consumers that the fuel is "available". This would require an additional 15,000 outlets nationwide, at a cost of $\$ 600$ million.

10. Based on sale of 1,000,000 light duty vehicles per year distributed to vehicle types and manufacturers in proportion to 1988 sales shares.

11. From DOE the Motor Fuel Consumption Model 14th Periodical Report, December 1988, DOE/OR/21400-H12. 
12. Plant cost estinates taken from DOE analysis of methane plant construction costs. Range of costs reflects differences in construction costs of plants in Areas II and III as defined in DOE Draft Report "Methanol Production Costs, Technical Report Two".

13. $\$ 53,000 /$ retail outlet includes proportional tank truck and terminal costs. Taken from Draft Report "Capital and Operating Cost of a Fuel Methanol Distribution System, 1988 Update", Oct. 1988, Energy and Environment Analysis, Inc.

14. \$275/vehicle incremental retail price as reported in "Characterization of Future Methanol Compatible Vehicle Attributes", Energy and Environmental Analysis, Inc., June 1989. Capital costs to manufacturers (fixed and variable) to produce vehicles are assumed equal to the cumulative price increase. 


\section{Prellminary Analysis of \\ Vebicle, Fuel Distribution, and Fuel Volume/Price Requiremeats(1) for \\ Cleas Air Act "Clean Fuels" Program: \\ Natural Gas}

M. Singh

$8 / 30 / 89$

PPA/DOE
I. Fuel Volumes(2)

(in Ozone Nonattainment Areas)

Natural Gas Used (Billion scf/yr) (3)

Gasoline Displaced (Billion gal/yr)

Gasoline Used (Billion gal/yr)

\section{Potebtial Fuel Price Changes}

Natural Gas Subsidy

@ 58/125 scf natural gas (Million) (4)

Gasoline Price Increase Required

to Support 5e/125 scf Subsidy(5)

\section{Natural Gas Demand Comparisions}

NGV Demand vs. Domestic Natural Gas Production(6)

NGV Demand vs. Residental/Commercial Demand

in Ozone Nonattainmen! Area(7)

IV. Refueling Outlets(8)

In Ozone Non-Attainment Areas to

Serve Flexible Fuel Vehicles (9)

V. Vehicles

Annual Sales(10)

Tolal Natural Gas Vehicles in Use(11) (Million)

* of LDVs in Ozone Nonattainment Areas

vI. Capital Costs - Cumulative (Billion)

Gas Exploration and Production(12)

Refueling Outets(13)

Vehicles(14)

See Explanatory Notes Allached

$\begin{array}{rrrr}40.0 & 311.2 & 498.8 & 603.8 \\ 0.3 & 2.5 & 4.0 & 4.8 \\ 23.1 & 23.6 & 24.4 & 25.4\end{array}$

$\begin{array}{llll}\$ 16 & \$ 125 & \$ 200 & \$ 242\end{array}$

$0.1 \& / \mathrm{gal} . \quad 0.5 \notin / \mathrm{gal} . \quad 0.8 \$ / g a l . \quad 1.0 \notin / 8 \mathrm{al}$.

$\begin{array}{llll}0.2 \% & 1.7 \% & 2.7 \% & 3.3 \% \\ 2.4 \% & 19.0 \% & 30.4 \% & 36.7 \%\end{array}$

$\begin{array}{llll}480 & 3,720 & 5,970 & 7.220\end{array}$

Cars

a

Ford

Chrysler

European

Asian

0.5

5.2

$10.7 \%$

9.5

$18.1 \%$

12.6

$1.1 \%$

\$0.03

S0.17

\$0.22

50.40

51.33

$\$ 0.36$

$\$ 2.14$

$\$ 8.20$
$\$ 0.43$

$\$ 2.59$

$\$ 12.20$
110,000

100,000

70,000 40,000 
Explanatory Hoteo: Natural Gas

1. 11 figures based on the proposal for ales of .5 gililon "clean fuel" light duty vehicles in 1995, .75 alion in 1996 and 1.0 milizon each year thereafter. in nine worst casne non-attainment areas. While the president program only proposes bles through 2004, it is expecter that bales of 1 million "clean Euel" vehicles will continue in subsequent yearg. The nine worbt ozone non-attainent areas have a population of 57 ililion people of 231 of U.s. population (source: IPA Office of Mobile sources\}. Vohicle populations and fuel use in affected aroas assured equal to 238 of U.S. total. 11 flgures are preliminary and subject to change.

2. Gasoline fuel voluwes taken from DOE Hotor pul consumption (MFC) Model l4th periodical Report Base case a modified by wethanol vohicle -ales chedule, reported in BUSkrun 1. DAT. In this analyois, natura: gas vehicle (NGV) ale $x$ eplace tho methanal vehicle solos asumed in this run. NGVB are asmumed to have the sume energy fficiency as gabolino - powered vehicles.

3. 358 utilization of NGV assumed, meaning that 258 of the time the aual-fuel vovis are outside ozone nonmattainment area and use gasolino.

4. ABsume 1000 Btu/sef. Actual subsidy required to equalize natural gas and gaboline prices dependi on factors that are can not be accurately esiduted at thio tise. 5chsct is ueed here an an exampie. If greater or lesser subsidy is required, these figures can be adjusted in direct proportion to the 125 oef subsiay.

5. Assumes only gasoline sold in orone nonmattainment areas bear tho price increase or tax.

5. Dowestic natural gas production Erom EIA' Annual Energy outlook 1989. Product on for 2000 assumed for years 2005 and 2010 .

7. $198 \mathrm{~T}$ residentiai/comercial demand in ozono nonattainnent areas estimated trox such cemand in 9 states in which the nine areas re located. State-ievel per copita demand from state Ereray Data Report (DOE/EIA-3214/87) and population of nonattainent areas tron State Metropoistan Ares Date Eook 1995.

z. Based on each outlet dispensing 83.6 lob seffyr.

9. If dedicated verisles are mandated, then adational outiess will be required (I) initjally in oxone areas and (2) outside the urban ereas to allow dedicated vehicles to travel Ereely. 108 is the rinimum fraction that otudies (on diosel vehiclo omers) have shown will bat infy consumers that the fuel is "available". This would reguire an additional 15,000 outlets nationwide, at a cost of $\$ 5.4$ bi11ion.

10. Based on sale of 1,000,000 Ilght Auty vehicles per year distributed to vehiclo types and anufacturers in proportion to 3988 ales shares.

i. Fron DOE the Motor Fuel Conaumption Model 14th periodical Report. December 1988, DOE/OR/21400 K12.

12. From Performance pyofiles of major Energy Producexs 1987. Assumes depreciation, depietjon and amortization costs represent capital costs for funding and producing natural gas in the v.s.

13. \$358,000/retail outlet includes cost of distxibution hook-up. Taken

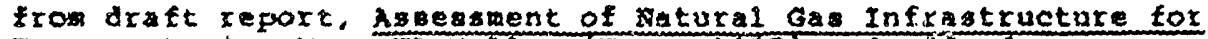
Izansportstion Use. EA Mulfer (kov." 198B) and ad́lendums.

14. \$800/vehicle incxemental retail price as reported in nsbessment of coste and senefits of plexible and Alternative funl use in the U.5. Transportation Sector, Progress Report Throc: Vehiclo and Fuel Distxibution Requirement (Draft) (Ju1y 1989). capitsl costs to manufocturexs (fined and variabie) to produce vohicies are asumed equal to the cumulative prlce increase. 
2. "Methanol vs. Natural Gas Vehicles: A Comparison of Resources Supply, Performance, Emissions, Fuel Storage, Safety, Costs, and Transitions." DeLuchi et alia, University of California, Davis, 1988. SAE Technical Paper \#881656.

a. Table 14: Input data for the reference gasoline vehicle

b. Table 15: Estimates of the cost of methanol from RNG (delivered), US gas, and US coal 1985\$

c. Table 17: Capital and operating costs of CNG stations

d. Table 18: Base-case input costs data for methanol vehicles

e. Table 19: Base-case input cost data for natural gas vehicles

f. Table 20: Life-cycle cost estimates for methanol and $N G$ vehicles 


\section{Table 14: Input data for the reference gasoline vehicle}

\begin{tabular}{l|l}
\hline 35 & Overall lifetime fuel economy, miles/gallon \\
\hline 9500 & The initial price of the car, with tax and license, 1985 U.S. \$ \\
\hline 130,000 & The life of the car, miles \\
\hline 0.03 & Vehicle salvage value, fraction of initial cost \\
\hline 10,000 & Miles driven per year \\
\hline 2535 & The weight of the vehicle, lbs \\
\hline 0.09 & The real annual interest rate, for auto loans or foregone savings \\
\hline 46.24 & Insurance payments, \$/month, first $n$ years \\
\hline 5 & n, years (see above) \\
\hline 30.57 & Insurance payments, \$/month, subsequent years \\
\hline 400 & Maintenance costs, \$/year \\
\hline 7.50 & Parking and tolls, \$/month \\
\hline 250.00 & Four replacement tires, \$/set \\
\hline 50,000 & Life of tires, miles \\
\hline 20.00 & Accessories, \$/years \\
\hline 11.00 & Oil, \$/year \\
\hline 90.00 & Registration, including inspection and maintenance cost, \$/year \\
\hline 0.20 & Gasoline tax, federal + average state, \$/gallon \\
\hline
\end{tabular}


Table 15: Estimates of the cost of methanol from RNG (delivered), U.S. gas, and U.S. coal $1985 \$ / \mathrm{mbtu}$ (higher heating value)*

\begin{tabular}{|c|c|c|c|c|c|c|c|c|}
\hline & Fluor & $\mathrm{KKPL}$ & $\begin{array}{c}\text { Cohen and } \\
\text { Muller }\end{array}$ & Chevron & $\begin{array}{c}\text { Jack Faucett } \\
\text { Associates }\end{array}$ & $\begin{array}{c}\text { Wagner and } \\
\text { Tatterson }\end{array}$ & Sperling & $\begin{array}{l}\text { Range used in } \\
\text { this paper }\end{array}$ \\
\hline Reference: & $\begin{array}{l}1981 \\
(160)\end{array}$ & $\begin{array}{l}1983 \\
(109)\end{array}$ & $\begin{array}{l}1985 \\
(161)\end{array}$ & $\begin{array}{r}1985 \\
(78)\end{array}$ & $\begin{array}{c}1986 \\
(38)\end{array}$ & $\begin{array}{l}1987 \\
(162)\end{array}$ & $\begin{array}{c}1988 \\
(27)\end{array}$ & \\
\hline RNG: & & 12.04 & 11.71 & 14.06 & 7.99 & 6.18 & $8.66-14.03$ & $9.00-12.50$ \\
\hline U.S. gas: & & $\cdots$ & 11.17 & 12.50 & 11.46 & 6.18 & $8.95-14.32$ & \\
\hline U.S. coal: & $10-11.50 t$ & 14.37 & $17-19.66 t t$ & 18.75 & -. & 13.80 & $13.43-23.28$ & $14.00-19.00$ \\
\hline
\end{tabular}

Note: Assumptions not identical in all cases. See ref. (76) for or review. As noted there, low-end estimates in the literature of the cost of methanol from RNG probably are valid only at relativel low levels of demand. Thus our range does not include the lower end of the range of estimates for methanol from RNG shown above. See ref. (163) for estimates of the marginal supply costs of associated and non-associated gas for the years 2000-2010. Those estimates do not include any economic rent.

- We use 65,900 Btu/gailor. if methanol.

+ Depends on finaricial 15 sisinptions.

t+ Depends on the sires of the plant. 
Table 16a: Estimated U.S. NG production, near- and middle-term scenarios

\begin{tabular}{lcccc}
\hline \multicolumn{4}{c}{ Production, TCF/year } \\
\hline & $\begin{array}{c}\text { Without NGVs in } \\
2000 \text { (EIA, 1988) }\end{array}$ & $\begin{array}{c}\text { Growth in Non- } \\
\text { NGV beyond 2000* }\end{array}$ & $\begin{array}{c}\text { Required for } \\
\text { NGVs }\end{array}$ & Total \\
\hline Near term & 17 & $0-3$ & $2-3$ & $19-23$ \\
Middle term & 17 & $0-3$ & $8-10$ & $25-30$ \\
\hline
\end{tabular}

* Additional production required to support growth in demand by non-transportation sectors, above the 17 TCF/year projected recently by the EIA (167) for 2000 (the left-hand column of this table.) We assume that high prices in the middle term keep gas demand in non-transportation sectors from growing more than 3 TCF/year above the Energy Information Agency (167) projection for 2000. 


\section{Table 17: Capital and operating costs of CNG stations}

\begin{tabular}{|c|c|c|c|c|c|c|c|}
\hline $\begin{array}{l}\text { Station } \\
\text { location }\end{array}$ & $\begin{array}{l}\text { Inlet } \\
\text { psi }\end{array}$ & $\begin{array}{c}\text { Car tank } \\
\text { psi }\end{array}$ & $\begin{array}{l}\text { Capacity } \\
\text { SCFM }\end{array}$ & $\begin{array}{l}\text { Installed } \\
\text { S/SCFM* }\end{array}$ & $\begin{array}{c}\text { mmBtu-power/ } \\
\text { mmBtu-CNG }\end{array}$ & $\begin{array}{l}\text { Maintenance } \\
\text { \$mmbtu-CNG }\end{array}$ & Reference \\
\hline Canada & 175 & 3000 & 65 & $2700^{* *}$ & 0.015 & & Topaloglu (86) \\
\hline U.S. & -- & $2400-3000$ & 30 & 2500 & -- & -- & $A G A(170)$ \\
\hline U.S. & -. & 2400 & 50 & $1600-2600$ & -- & -- & Areospace Corp. (7) \\
\hline Pacific Rim & $20-70$ & 2400 & $70^{* * *}$ & $2200^{* * *}$ & $0.055 t$ & -- & United Nations (171) \\
\hline New Zealand & 5 & 3000 & 60 & 2036 & 0.073 & 0.36 & Abram et al. (152)tt \\
\hline U.S. & 15 & $2400 \cdot 3000$ & 50 & $1700 t+t$ & -- & -. & Automotive Nat. Gás (172) \\
\hline U.S. & 5 & $2400-3000$ & 103 & $1400 \mathrm{ttt}$ & $-\cdot$ & -- & Automotive Nal. Gas (172) \\
\hline U.S. & -. & $2400-3000$ & 100 & 1250 & $-\cdot$ & -. & ACA (170) \\
\hline U.S. & & 2400 & 100 & $1250 \S$ & 0.033 & $0.20-0.70$ & Bechtold et al. (173) \\
\hline U.S. & 150 & $2400-3000$ & 100 & $1000 t+t$ & -. & -- & Automotive Nat. Gas (172) \\
\hline New Zealand & 50 & 3000 & 176 & 784 & 0.027 & 0.22 & Abram et al. (152)+t \\
\hline U.S. & -- & $2400-3000$ & 300 & 750 & $-\cdot$ & -- & AGA (170) \\
\hline New Zealand & 300 & 3000 & 265 & 570 & 0.021 & 0.22 & Abram et al. (152)t+ \\
\hline U.S./Canada & -- & $2200-3200$ & -. & -. & $0.03-0.05 \S \S$ & $0.14-0.18$ & Lefrenz et al. (174) \\
\hline U.S. & -- & 2400 & -- & -. & -- & 0.49 & Elms (175) \\
\hline U.S. & -- & -- & -. & -- & -- & 0.55 & Bechtold and Timbario (8) \\
\hline
\end{tabular}

Notes:

-- = Not specified SCFM - standard cubic feet per minute. In the U.S., most inlet pressures are 5 psig or less.

- Total installed capital cost per SCFM of capacity, including installation, storage, dispensing, and gas hook-up, but not including land, foundation, and buildings, unless otherwise noted.

" Described as "total acquisition cost," which apparently includes foundations and buildings.

*** Given as $\$ 146,000$ (we assume 1983\$) for station actually delivering 2000 gigajoules/month. We assume $60 \%$ capacity factor. Installation and materials costs are fairly high, and may reflect higher costs in lesser developed countries.

+ With our assumption of $\$ 17.50 / \mathrm{mmBtu}$ power (1983 U.S.\$), in New Zealand (price data from ref. [181]).

t+ We assume 1979 New Zealand dollars in original, $\$ 1.1 \mathrm{NZ}=\$ 1$ U.S. in 1979, $\$ 12.10 / \mathrm{mmBlu}$ for power (1979 U.S.\$).

$\mathrm{H+t}$ We assume $\$ 20,000-\$ 30,000$ for installation and gas-line hook-up.

$\S$ Given $\$ 85,000$ for the compressor in ref. and our assumption of $\$ 40,000$ for storage, dispensing, installation, gas hook-up.

$\$ \S$ Data in reference given in \$-electricity/mmBtu-CNG. We assume $\$ 16 / \mathrm{mmBtu}$-power (1980\$), average 1980 commercial sector price. 
Table 18: Base-case input cost data for methanol vehicles

\begin{tabular}{|c|c|c|}
\hline High & Low & \\
\hline 0.82 & 0.59 & Price of methanol from NG, a port or plant gate, $\$$ /gallon* \\
\hline 1.25 & 0.92 & Price of methanol from coal, plant gate, $\$ /$ gallon* \\
\hline 0.23 & 0.14 & Domestic transportation cost and retail mark-up, \$/gallon \\
\hline 0 & 0 & $\begin{array}{l}\text { Extra initial cost of the vehicle, including engine downsizing and pollution } \\
\text { control equipment, } \$\end{array}$ \\
\hline \multicolumn{2}{|c|}{130,000} & Life of the vehicle, miles \\
\hline 1.0 & 1.0 & Maintenance costs, fraction of gasoline vehicle's \\
\hline 1.10 & 1.20 & Thermal efficiency, relative to gasoline \\
\hline 0.11 & 0.11 & Fuel tax, Federal + average state, \$/gallon \\
\hline
\end{tabular}

Notes:

* From cost assumptions in Table 15, and assuming 65,900 BTU/gallon 
Table 19: Base-case input cost data for natural gas vehicles

\begin{tabular}{|c|c|c|c|c|}
\hline \multicolumn{2}{|c|}{ CNG } & \multicolumn{2}{|c|}{ LNG } & \\
\hline High & Low & High & Low & \\
\hline 9.00 & 7.50 & 9.00 & 7.50 & The cost of gas to the station, $\$ / \mathrm{mmBtu}$, near term \\
\hline 11.00 & 9.00 & 11.00 & 9.00 & The cost of gas to the station, $\$ / \mathrm{mmBtu}$, middle term \\
\hline 750 & 650 & - & - & Total capital cost of CNG station, \$/SCFM of capacity, excl. land and booth \\
\hline 250 & 250 & - & - & Capacity of compressor, SCFM \\
\hline 4200 & 4600 & -- & - & Hours compressor operates per year \\
\hline 10,000 & 10,000 & - & - & Cost of buildings for CNG station, \$ \\
\hline- & - & 1.00 & 0.925 & Installed capital cost of liquefier and booth, millions of $\$$ \\
\hline 50,000 & 30,000 & 70,000 & 40,000 & Cost of land, $\$$ \\
\hline 20 & 20 & 20 & 20 & Life of equipment, years \\
\hline 0.05 & 0.10 & 0.05 & 0.10 & Salvage value of station equipment at end of life \\
\hline 0.15 & 0.15 & 0.15 & 0.15 & Before-tax rate-rff-return on investment, decimal factor \\
\hline 70,000 & 50,000 & 95,000 & 60,000 & Staff salaries, total \$/year \\
\hline 0.075 & 0.035 & 0.23 & 0.18 & Compression or liquefaction energy requirement, $\mathrm{mmBtu}$ in $/ \mathrm{mmBtu}$ out \\
\hline 26.00 & 23.00 & 9.00 & 7.50 & Cost of fuel used to compress or liquefy NG, $\$ / \mathrm{mmBtu}$, near term \\
\hline 35.00 & 30.00 & 11.00 & 9.00 & Cost of fuel used to compress or liquefy NG, $\$ / \mathrm{mmBtu}$, middle term \\
\hline 0.50 & 0.25 & 0.20 & 0.16 & Maintnenace costs, $\$ / \mathrm{mmBtu}$ of LNG or CNG produced \\
\hline 0.02 & 0.01 & 0.02 & 0.01 & Yearly administration and general expenses, fraction of investment \\
\hline- & - & 1.03 & 1.01 & Boil-off loss at LNG station, factor \\
\hline-- & -- & --- & -- & $\cdots$ \\
\hline 4.21 & 2.24 & 4.55 & 2.83 & Retail fuel mark-up, before taxes, near term, $\$ / \mathrm{mmBtu}$ \\
\hline 4.88 & 2.49 & 5.01 & 3.10 & Retail fuel mark-up, before taxes, middle term, $\$ / \mathrm{mmBtu}$ \\
\hline-- & -- & 1.03 & 1.00 & Boil-off loss factor, for LNG vehicles \\
\hline 800 & 700 & 950 & 650 & Extra initial cost of fuel storage equipment, $\$$ \\
\hline 0.25 & 0.45 & 0.10 & 0.35 & Salvage value of fuel storage equipment, fraction of initial cost \\
\hline 250 & 350 & 250 & 350 & Cost reduction for foregone pollution control equipment, \$ \\
\hline 0 & 0 & 0 & 0 & Cost difference for underhood parts, including engine size, $\$$ \\
\hline 130,000 & 160,000 & 130,000 & 160,000 & Life of vehicle, miles \\
\hline 1.10 & 1.25 & 1.10 & 1.27 & Relative thermal efficiency \\
\hline 120 & 120 & 50 & 0 & Extra weight of vehicle, Ibs \\
\hline 1.0 & 0.8 & 1.0 & 0.8 & Relative yearly maintenance cost \\
\hline 0.6 & 0.4 & 0.6 & 0.4 & Relative yearly oil cost \\
\hline 1.05 & 1.0 & 1.05 & 1.0 & Relative monthly insurance cost, first $n$ years \\
\hline 1.0 & 1.0 & 1.0 & 1.0 & Fuel tax, relative to gasoline tax cost-per-mile \\
\hline
\end{tabular}

Notes: -- = not relevant. Fuel cost is higher for compression than for liquefaction because compressors use electricity, whereas small-liquefiers run off of gas from the pipeline. 
Table 20: Life-cycle cost estimates for methanol and NG vehicles

\begin{tabular}{|c|c|c|c|c|}
\hline \multicolumn{5}{|l|}{ Base case:* } \\
\hline \multirow[b]{3}{*}{ Vehicle } & \multicolumn{2}{|c|}{ Near term } & \multicolumn{2}{|c|}{ Middle term } \\
\hline & \multicolumn{2}{|c|}{ Break-even \$/gal** } & \multicolumn{2}{|c|}{ Break-even \$/g:" } \\
\hline & High & Low & Low & High \\
\hline Methanol & $\$ 2.00$ & $\$ 1.33$ & $\$ 2.74$ & $\$ 1.85$ \\
\hline LNG & $\$ 2.23$ & $\$ 0.75$ & $\$ 2.52$ & $\$ 0.92$ \\
\hline CNG & $\$ 2.14$ & $\$ 0.75$ & $\$ 2.46$ & $\$ 0.93$ \\
\hline \multicolumn{5}{|c|}{$35 \mathrm{mpg} / 350$ mile-range, or $25 \mathrm{mpg} / 250$ mile-range, CNG:*** } \\
\hline CNG & $\$ 2.29$ & $\$ 0.86$ & $\$ 2.60$ & $\$ 1.04$ \\
\hline \multicolumn{5}{|c|}{ NGVs with no pollution control (3-way catalysts): $t$} \\
\hline LNG & $\$ 2.11$ & $\$ 0.59$ & $\$ 2.40$ & $\$ 0.77$ \\
\hline CNG & $\$ 2.02$ & $\$ 0.60$ & $\$ 2.34$ & $\$ 0.78$ \\
\hline \multicolumn{5}{|c|}{$5 \%$ real interest rate: $+t$} \\
\hline LNG & $\$ 2.14$ & $\$ 0.64$ & $\$ 2.43$ & $\$ 0.81$ \\
\hline CNG & $\$ 2.06$ & $\$ 0.55$ & $\$ 2.37$ & $\$ 0.82$ \\
\hline \multicolumn{5}{|c|}{ High-pressure CNG inlet: $++t$} \\
\hline CNG & $\$ 1.93$ & $\$ 0.68$ & $\$ 2.19$ & $\$ 0.85$ \\
\hline
\end{tabular}

Notes: In all cases mpg refers to gasoline vehicles. Efficiency for alternative vehicles calculated relative to gasoline $\mathrm{mpg}$, from differences in vehicle weight and thermal efficiency.

* 35 mpg gasoline vehicle; 250 mile range for ail vehicles; $9 \%$ real auto-loan rate; NGVs have full pollution control; low-pressure gas inlet for CNG.

** The break-even price of gasoline is that price of gasoline which equates the full life-cycle cost-per-mile of the alternative-fuel vehicle with the full life-cycle cost-per-mile of the baseline gasoline vehicle.

*** Modelled by increasing the cost of fuel storage by a factor of 1.4 , and ignoring weight effects.

+ With $\$ 250$ to $\$ 350$ reduction for foregone pollution control equipment.

++ The real rate of interest foregone by a cash purchaser. The $9 \%$ base case is a real auto-loan rate.

$+++\$ /$ SCFM changed to $\$ 500-\$ 600$; energy requirement to $0.015-0.020 \mathrm{mmBtu}$-power $/ \mathrm{mmBtu}-\mathrm{CNG}$;

maintenance requirement to $\$ 0.15-0.25 / \mathrm{mmBtu}-\mathrm{CNG}$ 
3. "Is Methanol the Transportation Fuel of the Future?" Daniel Sperling and Mark A. DeLuchi, 1989. Transportation Research Group, University of California, Davis. a. Table 2: Start-up barriers for methanol and CNG multifuel vehicles relative to gasoline

Tabie 2. Seamt-up arriers for mehanel and cws witeffuel vehteles reiative to gaselines based on hers. 17, 21, 22, and 42

\begin{tabular}{|c|c|c|}
\hline Paramerer & Methanot & CNG \\
\hline 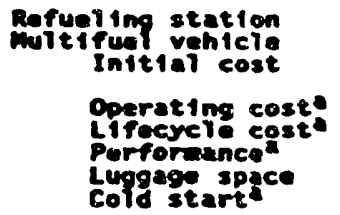 & $\begin{array}{l}\$ 40,000 \\
+\$ 0 \text { to } 200 \\
\text { the sam or woro } \\
\text { the same or wore } \\
\text { the sam or better } \\
\text { the saine } \\
\text { worse }\end{array}$ & $\begin{array}{l}\$ 300,000 \text { or wore } \\
+\$ 1600 \text { (retrofit) } \\
+\$ 50 \text { (factory) } \\
\text { iess or more } \\
\text { iess or worse } \\
\text { iass } \\
\text { the som }\end{array}$ \\
\hline
\end{tabular}

For oparation on the won-gasoline fuel. 
4. "Electric Vehicles: Performance, Life-Cycle Costs, Emissions, and Recharging Requirements." DeLuchi, et alia, 1989. Transportation Research Group, University of California, Davis.

a. Table 5: Base-case input data for reference gasoline vehicles

b. Table 7: Base-case input data and calculated results for EVs

c. Table 8: Cost comparison of gasoline and electric passenger vehicles, calculated results, cents $/ \mathrm{mi}$

Trble 5. Base-case input duta for the reference grsoline vehicles

\begin{tabular}{|c|c|}
\hline $\begin{array}{l}30.5 \\
19.0 \\
10,500 \\
14,000 \\
38 \\
120,000 \\
10,000 \\
2600 \\
4000 \\
46.24 \\
5 \\
30.57 \\
400 \\
7.50 \\
250.00 \\
50.000 \\
20.00 \\
11.00 \\
25 \\
40 \\
20 \\
0.20 \\
98 \\
52 \\
78 \\
58\end{array}$ & 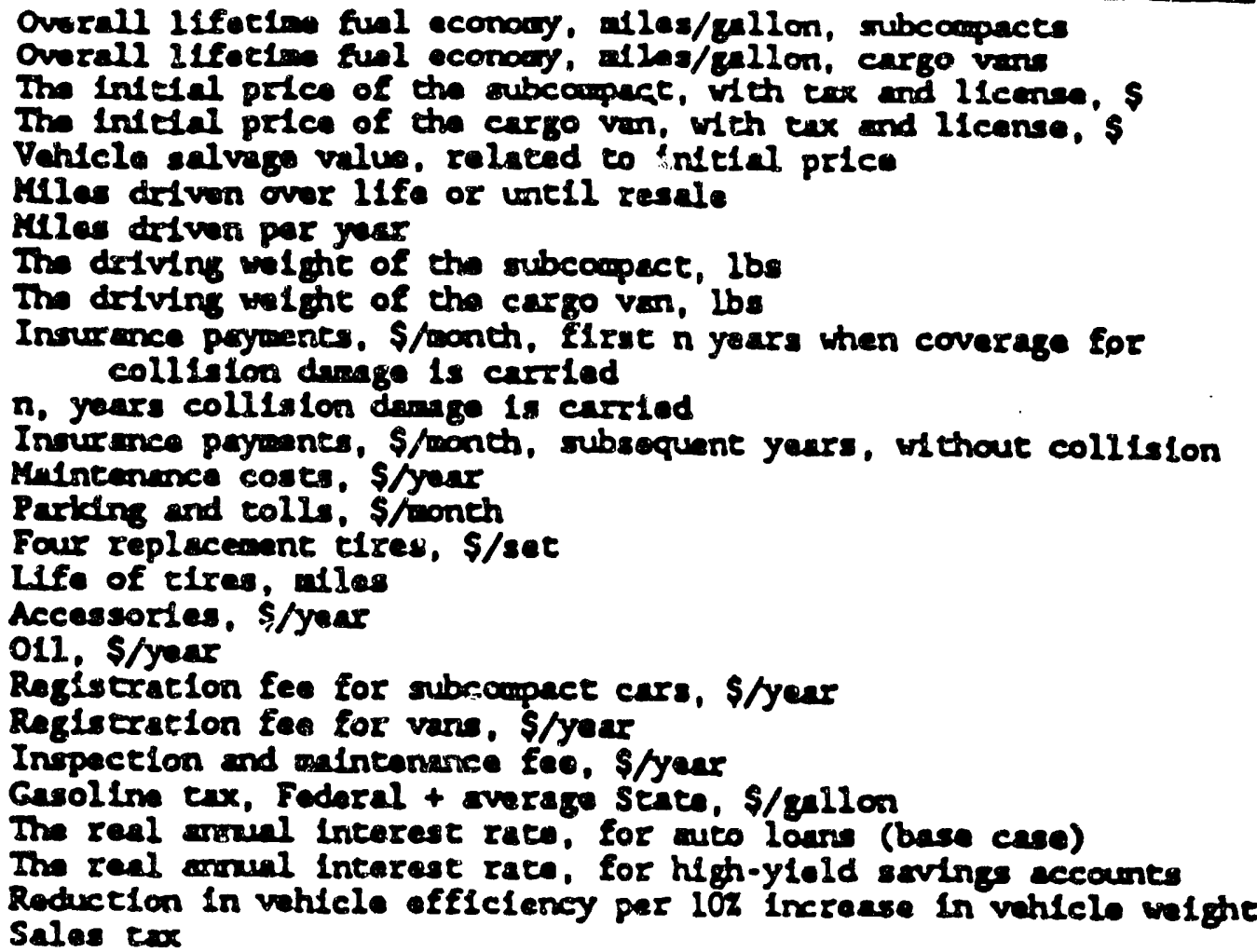 \\
\hline
\end{tabular}

Accessory cost insurance cost, mintenmes cost, and parking and tolls

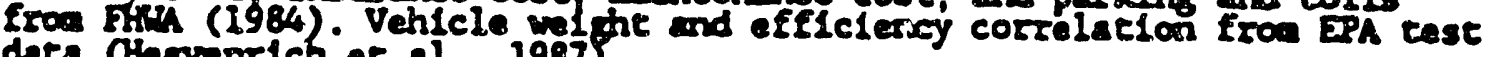
dates Aleverulch et al.. 1987\}. 
Tablo 7. Base-case lpput data and caloulated realts for 2V:

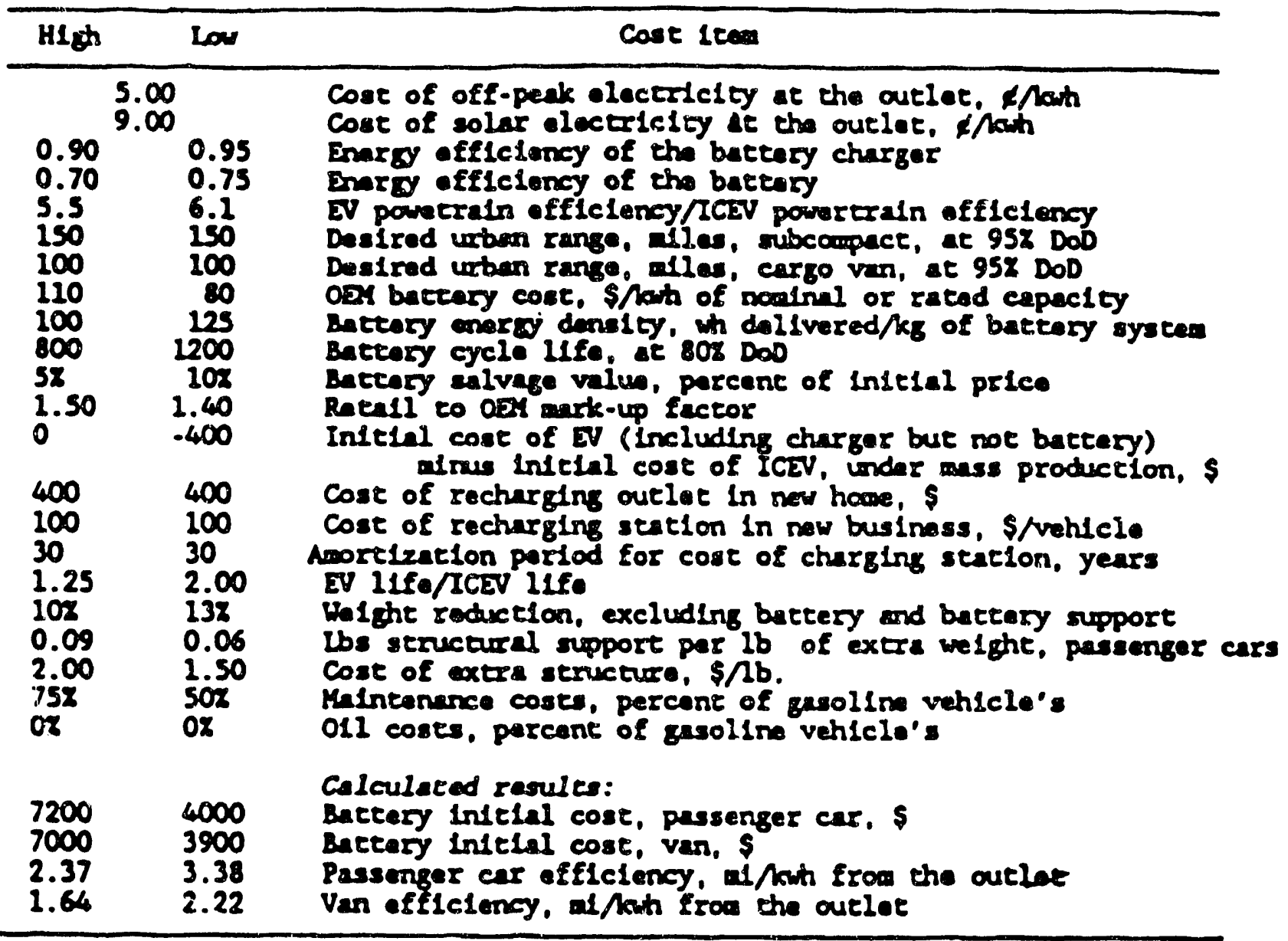


Irble 8. Cont coparison of yeolino and electric paseenger whiclas, calculated revilen, cents/at

\begin{tabular}{|c|c|c|c|}
\hline $\begin{array}{l}\text { Gasolim } \\
\text { vahiele }\end{array}$ & Cost Iten & $\begin{array}{c}\text { Eleceric } \\
\text { Low }\end{array}$ & $\begin{array}{r}\text { Vehlele } \\
\text { HIgh }\end{array}$ \\
\hline $\begin{array}{c}3.77 \\
13.94 \\
0.9 \\
4.69 \\
4.47 \\
1.55\end{array}$ & 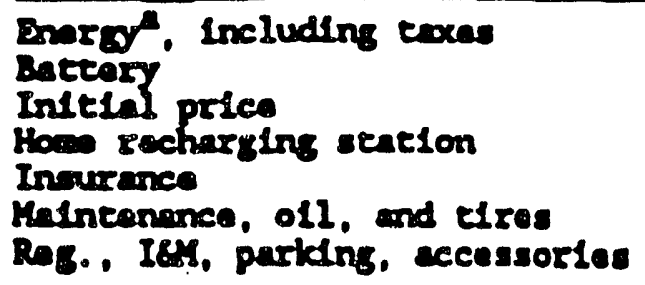 & $\begin{array}{l}1.48 \\
4.51 \\
9.90 \\
0.39 \\
4.67 \\
2.44 \\
1.38\end{array}$ & $\begin{array}{rr} & 2.11 \\
- & 10.56 \\
-12.55 \\
0.39 \\
-\quad 5.21 \\
-\quad 3.48 \\
-\quad 1.43\end{array}$ \\
\hline 4 & TOLAL & 24.77 & -35.73 \\
\hline
\end{tabular}

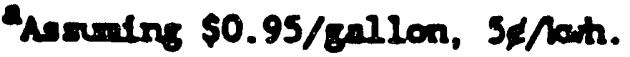


5. "Curbing Air Pollution in Southern California: The Role of Electric Vehicles." Lamont C. Hempel, et alia, April 1989. The Claremont Graduate School - Center for Politics and Policy.

a. Table 5: Current lifecycle cost comparisons for electric and gasoline-powered vans

b. Table I-4: Annual electricity requirements for EVs under three scenarios

c. Table I-5: Estimated lifecycle cost comparisons for gasoline, methanol, and advanced next-generation electric vehicles

TABLE 5

CURRENT IIFECYCLE COST COMPARISONS FOR

ELECTRIC AND GASOLINE-POWERED VANS *

(cents per mile, in 1985 currency, at $12,000 \mathrm{ml} / \mathrm{Yr}$.)

COST FACTOR

Inttial cost of vehicle*

Fuel cost

Battery cost

Insurance

Maintenance

O11 and accessorles

Replacement tires

Parking and tolls

registration and taxes

Fuel tax

TOTAL PRIVATE COST

$\begin{array}{cc}\text { TYPE OF VAN } \\ \frac{\text { Electric }}{14.16(24.25)} \frac{\text { Gasoline }}{16.42} \\ 4.45 & 5.00 \\ 1.0 .0 .9 & --- \\ 7.50 & 7.59 \\ 3.13 & 6.25 \\ 0.84 & 1.08 \\ 1.05 & 0.52 \\ 1.00 & 1.00 \\ 4.36 & 3.33 \\ 0.05 & 0.60 \\ 46.63 & 42.19\end{array}$

*Assumes EV production volumes at $50,000 / y r$; EV efficiency at $1.5 \mathrm{ml} / \mathrm{kWh}$ from outlet, at $7 \mathrm{c} / \mathrm{kWh}$, with $60 \mathrm{mile}$ range and battery cost of $\$ 3,868$, base price of conventional van at $\$ 13,400$, with gasoline lifetime fuel efflclency of $18 \mathrm{mpg}$. welght of 3800 1bs.: annual interest rate of $10 \%$ insurance avg. at $\$ 75 /$ month: vehlcle l1ves of 130,000 ml. for gasoline and $180,000 \mathrm{ml}$. for electric. "Without battery.

Source: Iotus 1-2-3 spreadsheet model developed by Mark Deluch1, University of Callfornla, Dav1s, 1987. Assumptions used are our own. 
TABLE I-4

ANATAL ELECTRICITY REQUIREMENTS FOR EVS UNDER THREE SCENARIOS (in gWh/Yr)

\begin{tabular}{|c|c|c|c|c|c|c|}
\hline \multicolumn{2}{|c|}{$\begin{array}{l}\text { EV Fleat sizo } \\
\text { for each } \\
\text { Scenario } \\
\text { in the } \\
\text { Year } 3010\end{array}$} & \multirow{2}{*}{$\begin{array}{l}\text { EVs } \\
\text { as } \\
\text { tof } \\
\text { Total } \\
\text { Eleet } \\
\text { 5t }\end{array}$} & \multicolumn{4}{|c|}{$\begin{array}{l}\text { EV EfIiclency from Battery } \\
\text { in miles per kWh (efflelency } \\
\text { from outlet in parentheses) }\end{array}$} \\
\hline I. & 542,800 & & 3,924 & 2,616 & 1,962 & 1,570 \\
\hline II. & $2,763,300$ & $25:$ & 19,976 & 13,317 & 9,988 & 7,990 \\
\hline III. & $5,069,300$ & 47t & 36,646 & 24,430 & 18,323 & 14,658 \\
\hline
\end{tabular}




\section{TABLE I-5}

ESTIMATED IIFECYCLE COST COMPARI8ONS FOR GASOLINE METHANOL, AND ADVANCED "NEXT GENERATION" ELECTRIC VEHICLES *

(conte per alle, in 1985 currency, at $12,000 \mathrm{ml} / \mathrm{yr}$. )

COST FACTOR

Initlal cost of vablele(1)

Fued cost(2)

Battary cost(3)

Insurance (4)

Madntenance (5)

011 and accessortes(6)

Replacement tirea (7)

Parking and tolla(8)

Vehlcle registration(9)

Fuel tax (10)

TOTAT PRIVATE COST
TYPE OP PASSENGER VEHICLE Electric Gasoline rethaned

$12.55(28.40) \quad 14.70 \quad 14.70$

$\begin{array}{lll}2.51 & 3.00 & 5.48\end{array}$

5.85

5.00

5.08

5.08

1.24

3.75

3.75

0.46

0.60

0.60

0.73

0.44

0.44

1.00

1.00

1.00

2.28

1.00

1.00

0.03

0.60

0.60

30.64

- Xssumes mas production of EV w1th hlgh performance advanced batterles, on-board chargerw, and ac powartraina.

Sources Iotus 1-2-3 apreadaheet model developed by Mark Daluchl, Univeraity of Cal1sornia, Dav1s, 1987. Asmumptone used are our own:

(1) purchase price: $E V=\$ 15,433(16.4 \$ / m 1)$ with battory included, $\$ 12,200(12.65 \mathrm{c} / \mathrm{mL}$ ) w1thout gasoline vahlele = \$12,000, mothanol vahlcle $=\$ 12,000$; asaumea -tandard loan at 10 t and expected vahlele Ilves of 130,000 miles for gasoline and mothanol vehleles and $180,000 \mathrm{ml}$. Lor EV (longer $\mathrm{EV}$ Ilfe is due primarily to lack of englne vibration and wear). 
6. "Assessment of Costs and Benefits of Flexible and Alternative Fuel Use in the US Transportation Sector: Progress Report I - Context and Analytical Framework." January, 1988, USDOE.

a. Table 2: Summary of fuel and vehicle characteristics when alternative energy sources replace gasoline b. Table A-1: Summary of alternative-fuel prices and assessment of their suitability relative to gasoline c. Table E-1: Comparative summary of vehicle characteristics and cost for gasoline, diesel and alternative fuels 


\section{Table 2 - Summary of Fuel and Vehicle Characteristics When Alternative Energy Sources Replace Gasoline}

\begin{tabular}{|c|c|c|c|c|}
\hline & Ethanol & Methanol & CNG & Electricity \\
\hline $\begin{array}{l}\text { Near-Term Technical } \\
\text { Acceptability }\end{array}$ & Proven & Proven & $\begin{array}{l}\text { Satisfactory for } \\
\text { some uses }\end{array}$ & Close to commercial \\
\hline $\begin{array}{l}\text { Economic } \\
\text { Competitiveness } \\
\text { (for energy output) }\end{array}$ & $\begin{array}{l}\text { Much more } \\
\text { expensive }\end{array}$ & $\begin{array}{l}\text { Near } \\
\text { equivalent }\end{array}$ & $\begin{array}{l}\text { The same or } \\
\text { better }\end{array}$ & $\begin{array}{l}\text { More } \\
\text { expensive; } \\
\text { wide range }^{b}\end{array}$ \\
\hline Availability & Limited & $\begin{array}{l}\text { Limited; good } \\
\text { future potential }\end{array}$ & Limited & $\begin{array}{l}\text { Limited by generation } \\
\text { constraints }\end{array}$ \\
\hline $\begin{array}{l}\text { Fuel Volume, Com- } \\
\text { pared With Gasoline }\end{array}$ & $1.5 x$ & $2 x$ & $5 x$ & $2 x-3 x^{c}$ \\
\hline $\begin{array}{l}\text { Refueling } \\
\text { Procedure }\end{array}$ & $\begin{array}{l}\text { No different } \\
\text { from gasoline }\end{array}$ & $\begin{array}{l}\text { No different } \\
\text { from gasoline }\end{array}$ & $\begin{array}{l}\text { More complex } \\
\text { and lengthy }\end{array}$ & $\begin{array}{l}\text { Recharging takes } \\
\text { hours; battery } \\
\text { replacement } \\
\text { cumbersome }\end{array}$ \\
\hline $\begin{array}{l}\text { Fuel Storage } \\
\text { Container Weight }\end{array}$ & $1.3 x$ & $1.6 x$ & $\begin{array}{l}100-140 \times \text { (steel): } \\
50-i 0 \times \text { (aluminum) }\end{array}$ & $\begin{array}{l}\text { Heavy; depends } \\
\text { on technology }\end{array}$ \\
\hline $\begin{array}{l}\text { Fuel Storage } \\
\text { Tank Cost }\end{array}$ & Nominal & Nominal & $\$ 850-1,000$ & $\begin{array}{l}\text { Battery type deter- } \\
\text { mines equivalence }\end{array}$ \\
\hline $\begin{array}{l}\text { Current State of Fuel } \\
\text { System Technology } \\
\text { Development }\end{array}$ & $\begin{array}{l}\text { Production } \\
\text { technology in } \\
\text { Brazil }\end{array}$ & $\begin{array}{l}\text { Pre-production } \\
\text { stage }\end{array}$ & $\begin{array}{l}\text { Commercial, but } \\
\text { requires updating }\end{array}$ & $\begin{array}{l}\text { Being used in } \\
\text { niche markets }\end{array}$ \\
\hline $\begin{array}{l}\text { Representative } \\
\text { Type of Vehicle }\end{array}$ & $\begin{array}{l}\text { Light and } \\
\text { heavy duty }\end{array}$ & $\begin{array}{l}\text { Light and } \\
\text { heavy duty }\end{array}$ & $\begin{array}{l}\text { Niche fleets; light } \\
\text { and heavy duty }\end{array}$ & $\begin{array}{l}\text { Short range, } \\
\text { light duty }\end{array}$ \\
\hline $\begin{array}{l}\text { Engine Performance } \\
\text { Characteristics }\end{array}$ & $\begin{array}{l}\text { Power gain, but } \\
\text { less than methanol }\end{array}$ & $\begin{array}{l}\text { Approximately } 8 \% \\
\text { power gain॰ }\end{array}$ & $\begin{array}{l}\text { Approximately } 10 \% \\
\text { power loss }\end{array}$ & $\begin{array}{l}\text { Comparable, at ex- } \\
\text { pense of range }\end{array}$ \\
\hline $\begin{array}{l}\text { Exhaust Emissions: } \\
\mathrm{HC}, \mathrm{CO}, \mathrm{NO}_{\mathrm{x}} \text { and } \\
\mathrm{HC} \text { reactivity }\end{array}$ & $\begin{array}{l}\text { Same or better; } \\
\text { lower NO and } \\
\text { HC reactivity }\end{array}$ & $\begin{array}{l}\text { Same or better; } \\
\text { lower } \mathrm{NO}_{\mathrm{x}} \& \mathrm{HC} \\
\text { reactivity; potential } \\
\text { for lower CO }\end{array}$ & $\begin{array}{l}\text { NO: same or higher } \\
\text { HC: same or higher' } \\
\text { CO: lower }\end{array}$ & $\begin{array}{l}\text { Only emissions from } \\
\text { generating plants (var- } \\
\text { iable with facilities) }\end{array}$ \\
\hline
\end{tabular}

Energy Content (Net)

Compared with about 18,500-19,000 BTU/1b 11,500 8,600 $21,300^{\prime}$

N.A. for gasoline and diesel

\section{Compared with \\ $112,000-128,000$ BTU/gal for gasoline and diesel} 75,700 56,600 $22,800^{\prime}$ N.A.

\footnotetext{
- Depends on vehide operational characteristics and refueling costs. which are linked to the natural gas rates assigned to transport uses
by regulatory bodies. - Depends on battery tectinology and electricity costs (which have a wide range, based on variations in produc tion technology and local
regulation).

- Based on equivalent driving range.

-Twenty-gallon gasoline tank equivalent.

- Based on ongines optimized to use gasoline (methanol optimization yields higher gains).

'Pure methane. Othar minor constituents (such as ethane and propane) boil ai higher temperatures.

- Under "lean-bum" conditions. 
Table A-1 - Summary of Alternative-Fuel Prices and Assessment of Their Suitability Relative to Gasoline

\begin{tabular}{|c|c|c|c|c|c|c|}
\hline \multirow{2}{*}{$\begin{array}{l}\text { Alternative } \\
\text { Fuel }\end{array}$} & \multicolumn{2}{|c|}{ U.S. End-User Price Range } & \multirow{2}{*}{$\begin{array}{l}\text { Tochnical } \\
\text { Acceprability }\end{array}$} & \multirow{2}{*}{$\begin{array}{c}\text { Economic } \\
\text { Competitiveness }\end{array}$} & \multirow{2}{*}{$\begin{array}{c}\text { Environmental } \\
\text { Acceptance }\end{array}$} & \multirow[b]{2}{*}{ Availability } \\
\hline & Unit Price & \$Million BTU & & & & \\
\hline \multicolumn{7}{|l|}{ Gasoline } \\
\hline Regular & $\$ 0.53-0.65 / \mathrm{gal}{ }^{\star}$ & $4.2-5.1$ & - & - & - & - \\
\hline Premium & $\$ 0.60-0.78 / \mathrm{gal}^{\circ}$ & $4.7-6.2$ & - & - & - & - \\
\hline LPG (HD.5) & $\$ 0.23-0.33 / g a p$ & $2.8 \cdot 4.0$ & Lagging behind & Same or better & Same or better & Limited \\
\hline Ethanol & $\$ 1.25-1.45 /$ gak $^{\mathrm{c}}$ & $14.9 \cdot 17.2$ & Proven & $\begin{array}{c}\text { Much more } \\
\text { expensive }\end{array}$ & Favorable & Limited \\
\hline Methanol & $\$ 0.35-0.45 / \mathrm{gal}^{\triangleleft}$ & $5.5 \cdot 7.0$ & Proven & Near equivalent & $\begin{array}{l}\text { Much more } \\
\text { favorable }\end{array}$ & $\begin{array}{l}\text { Limited; good } \\
\text { future potential }\end{array}$ \\
\hline \multicolumn{7}{|l|}{ Natural Gas } \\
\hline $\begin{array}{l}\text { Residential } \\
\text { Commercial }\end{array}$ & $\begin{array}{l}\$ 3.62-8.66 / 1000 \mathrm{scf} \\
\$ 2.18-7.46 / 1000 \mathrm{scf}\end{array}$ & $\begin{array}{r}3.5-8.3^{\circ} \\
2.1-7.1\end{array}$ & $\begin{array}{l}\text { Satisfactory } \\
\text { for some uses }\end{array}$ & Same or better & Favorable & Limited? \\
\hline \multicolumn{7}{|l|}{ Electricity } \\
\hline $\begin{array}{l}\text { Residential } \\
\text { Commercial }\end{array}$ & $\begin{array}{l}\$ 0.015-0.133 / k W h \\
\$ 0.006^{n}-0.127 k W h\end{array}$ & $\begin{array}{l}4.2-37.9^{n} \\
1.7-36.1\end{array}$ & $\begin{array}{l}\text { Close to } \\
\text { commercial }\end{array}$ & $\begin{array}{l}\text { Wide } \\
\text { range' }\end{array}$ & $\begin{array}{l}\text { Same to much } \\
\text { better }\end{array}$ & $\begin{array}{l}\text { Limited due } \\
\text { to generation } \\
\text { constraints }\end{array}$ \\
\hline \multicolumn{7}{|l|}{ Synfuels } \\
\hline $\begin{array}{l}\text { Coal } \\
\text { Shale }\end{array}$ & $\overline{-}$ & $\overline{-}$ & $\begin{array}{l}\text { Similar } \\
\text { Similar }\end{array}$ & $\begin{array}{c}\text { More expensive } \\
\text { Unknown }\end{array}$ & $\begin{array}{l}\text { Unresolved } \\
\text { Unresolved }\end{array}$ & $\begin{array}{l}\text { NA } \\
\text { NA }\end{array}$ \\
\hline Hydrogen & - & - & $\begin{array}{l}\text { Requires } \\
\text { development }\end{array}$ & More expensive & Very favorable & NA \\
\hline
\end{tabular}

-R.A.C. prices without Federal or State taxes.

-Wholesale prices.

'FOB plant.

- FOB plant or port at current production levels.

- Does not anticipate any special rates for transportation vehicles.

'Depends on vehicle operational characteristics and refueling costs.
- Requires refueling infrastructure development; declining reserve base similar to petroleum; pipeline limitations.

"The extreme price range of electricity is due to production technology and regulation.

- Depends on battery technology and electricity costs.

i Depends on production technology.

"For industrial sector.

NA $=$ No available at present .

Table A-1 reinforces the assessment that methanol is the only alternative fuel that meets all the practical requirements for a broad-use transportation fuel. This is not to say that the other fuels cannot ever compete or that they should not be pursued. Each has niche markets that can be penetrated more effectively. However, methanol appears to be the only one with potential to make significant inroads into the U.S. transportation fuel market during the next dozen years or so. 


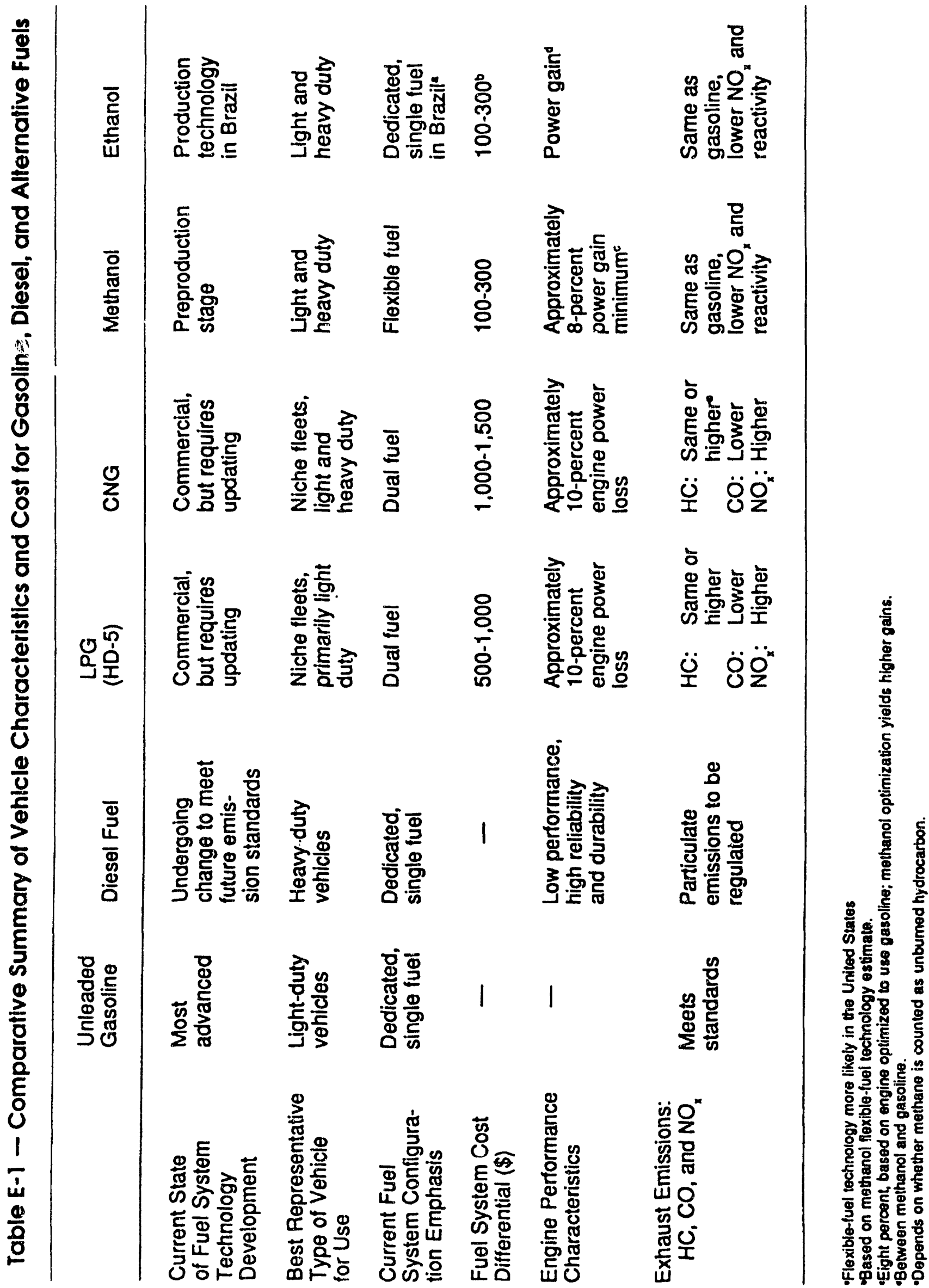


7. "Alternative Transport Fuels from Natural Gas." Rene Moreno and D.G. Fallen Bailey. June, 1989. World Bank Technical Paper \# 98.

a. Annex 3: Model based on natural gas price tracking oil prices

b. Comparative costs of various fuels of different distribution and delivery scenarios (p.93-100)

c. Table IV-10: Break even crude oil price levels compared to natural gas based on prices tracking oil prices 
a. Annex 3: Model based on natural gas price tracking oil prices

\begin{tabular}{|c|c|c|c|c|c|}
\hline VEHICEE SPECITTC TIONS? & $\mathrm{C}_{\mathrm{rr}} \mathrm{Prsenger}$ & Trucht & Truata & Trais: & Butur. \\
\hline Conventional fuel type: & gasoline & gasoline & diesel & gasoline & diesel \\
\hline Miles per gallon & 30.4 & 23.5 & 5.2 & 30.4 & 7.1 \\
\hline Kms per liter & 12.9 & 10.0 & 2.2 & 12.9 & 3.0 \\
\hline Liters per Km & 0.08 & 0.10 & 0.45 & 0.08 & 0.33 \\
\hline BTU's per Km & 2,624 & 3,394 & 16,482 & 2,624 & 12,071 \\
\hline Vebicle Life Years & 14 & 12 & 10 & 14 & 12 \\
\hline Annual Mileage (Kms) & 12,000 & 19,000 & 22,000 & 96,000 & 60,000 \\
\hline \multicolumn{6}{|l|}{ Conversion Cost: } \\
\hline CNG & $\$ 1,000$ & $\$ 1,800$ & $\$ 4,500$ & $\$ 1,800$ & $\$ 4,500$ \\
\hline LPG (Propane) & $\$ 700$ & $\$ 900$ & $\$ 3,500$ & $\$ 900$ & $\$ 4,800$ \\
\hline Methanol & $\$ 350$ & $\$ 500$ & $\$ 3,200$ & $\$ 500$ & $\$ 4,300$ \\
\hline Discount Rate on Conversion & $10 \%$ & $10 \%$ & $10 \%$ & $10 \%$ & $10 \%$ \\
\hline \multicolumn{6}{|l|}{ Annuitizod Convarsion Coda: } \\
\hline CNG & $\$ 136$ & $\$ 264$ & $\$ 732$ & $\$ 244$ & $\$ 660$ \\
\hline Propane & $\$ 95$ & $\$ 132$ & $\$ 570$ & $\$ 122$ & $\$ 704$ \\
\hline Methanol & $\$ 48$ & $\$ 73$ & $\$ \$ 21$ & $\$ 68$ & $\$ 631$ \\
\hline \multicolumn{6}{|l|}{ FUEL SPECIIIT A NONS: } \\
\hline & १ Gasoline & Diesel & CNG & Propone & Methinol \\
\hline Mega Joules per $\mathrm{kg}$ & 47.70 & 44.70 & & 45.70 & 20.02 \\
\hline BTU per cubic foot & & & 1000 & & \\
\hline Specific Gravity (kg/liter) & 0.75 & 0.86 & & 0.51 & 0.80 \\
\hline Mega Joules per liter & 35.78 & 38.44 & & 23.31 & 16.02 \\
\hline \multicolumn{6}{|l|}{ Delivered fuel prices } \\
\hline Crude Oil & harrel & & & & \\
\hline Natural gas & /Mef. & & & & \\
\hline $0-5 \mathrm{~km}(5 /$ liter $)$ & $\$ 0.159$ & $\$ 0.166$ & & S0.103 & S0.153 \\
\hline $0-5 \mathrm{~km}$ (\$/MMBTU) & $\$ 4.69$ & $\$ 4.56$ & $\$ 5.20$ & $\$ 4.67$ & $\$ 10.10$ \\
\hline $300 \mathrm{~km}$ (S/liter) & So.182 & $\$ 0.189$ & & $\$ 0.128$ & S0.176 \\
\hline $300 \mathrm{~km}$ (S/MMBTU) & $\$ 5.37$ & $\$ 5.19$ & $\$ 7.77$ & $\$ 5.79$ & $\$ 11.62$ \\
\hline
\end{tabular}




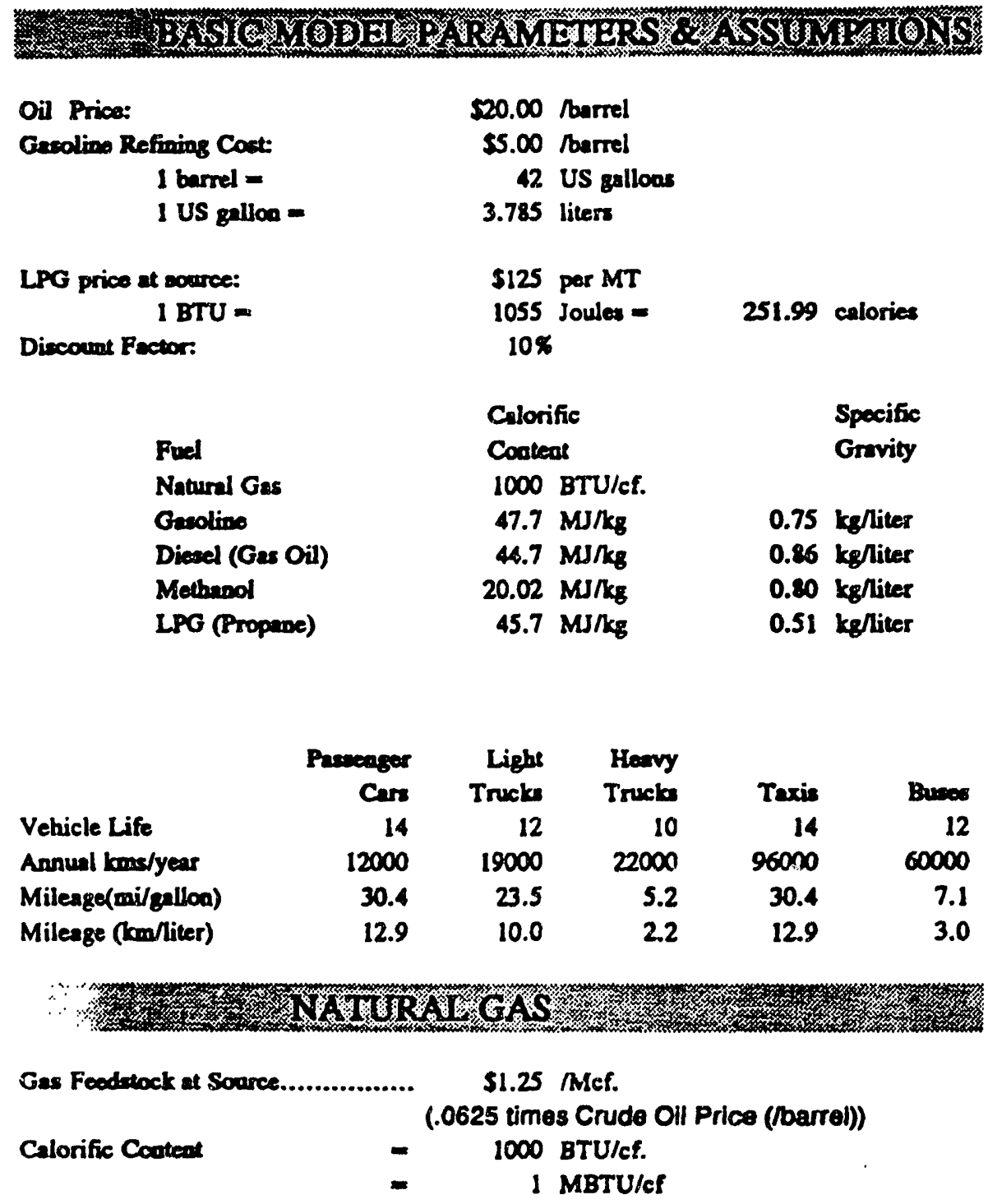




\begin{tabular}{|c|c|c|c|c|c|c|c|}
\hline \multirow{4}{*}{$\begin{array}{l}\text { Dirtance } \\
\text { from } \\
\text { Supply }\end{array}$} & \multirow[b]{2}{*}{ Crode } & & & \multicolumn{4}{|c|}{ FUEL COST (Ceats per low) } \\
\hline & & \multicolumn{2}{|c|}{$\begin{array}{l}\text { FUEL COST } \\
\text { (cent per liter) }\end{array}$} & \multirow{2}{*}{\multicolumn{4}{|c|}{ Car }} \\
\hline & Oil & & & & & & \\
\hline & $\begin{array}{c}\text { Prico } \\
\text { (S/barrel) }\end{array}$ & gesoline & diased & Easolive & geoline & dienel & diend \\
\hline $0-5 \mathrm{~km}$ & $\$ 20$ & 15.89 & 16.61 & 1.23 & 1.59 & 7.51 & 5.50 \\
\hline $50 \mathrm{~km}$ & $\mathbf{5 2 0}$ & 16.27 & 16.99 & 1.26 & 1.63 & 7.68 & 5.63 \\
\hline $100 \mathrm{ksn}$ & $\mathbf{2 0}$ & 16.65 & 17.37 & 1.29 & 1.67 & 7.85 & 5.75 \\
\hline $300 \mathrm{~km}$ & $\$ 20$ & 18.20 & 18.92 & 1.41 & 1.82 & 8.56 & 6.27 \\
\hline \multirow{3}{*}{\multicolumn{2}{|c|}{ 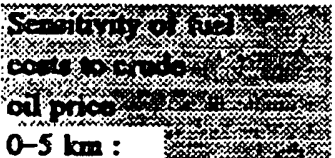 }} & \multirow{2}{*}{\multicolumn{2}{|c|}{$\underset{-c e n t s / l i t e r}{g}$}} & \multicolumn{4}{|c|}{ 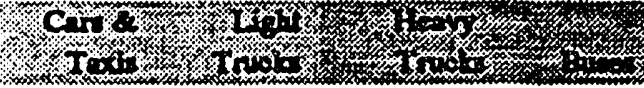 } \\
\hline & & & & 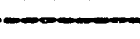 & -cents/km & 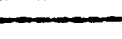 & \\
\hline & & & & & & & \\
\hline & $\$ 10$ & 9.60 & 10.03 & 0.74 & 0.96 & 4.54 & 3.32 \\
\hline & 20 & 15.89 & 16.61 & 1.23 & 1.59 & 7.51 & 5.50 \\
\hline & 30 & 22.18 & 23.18 & 1.72 & 2.22 & 10.48 & 7.68 \\
\hline & 40 & 28.47 & 29.75 & 2.20 & 2.85 & 13.46 & 9.86 \\
\hline & so & 34.76 & 36.33 & 2.69 & 3.48 & 16.43 & 12.03 \\
\hline & 60 & 41.05 & 42.90 & 3.18 & 4.11 & 19.40 & 14.21 \\
\hline & 70 & 47.34 & 49.47 & 3.66 & 4.74 & 22.38 & 16.39 \\
\hline & 80 & 53.63 & 56.05 & 4.15 & 5.37 & 25.35 & 18.57 \\
\hline & 90 & 59.92 & 62.62 & 4.64 & 6.00 & 28.33 & 20.75 \\
\hline & 100 & 66.21 & 69.19 & 5.12 & 6.63 & 31.30 & 22.92 \\
\hline $300 \mathrm{~km}$ : & $\$ 10$ & 11.91 & 12.34 & 0.92 & 1.19 & 5.58 & 4.09 \\
\hline & 20 & 18.20 & 18.92 & 1.41 & 1.82 & 8.56 & 6.27 \\
\hline & 30 & 24.49 & 25.49 & 1.90 & 2.45 & 11.53 & 8.44 \\
\hline & 40 & 30.78 & 32.06 & 2.38 & 3.08 & 14.50 & 10.62 \\
\hline & so & 37.07 & 38.64 & 2.87 & 3.71 & 17.48 & 12.80 \\
\hline & 60 & 43.36 & 45.21 & 3.36 & 4.34 & 20.45 & 14.98 \\
\hline & 70 & 49.65 & 51.79 & 3.84 & 4.97 & 23.42 & 17.16 \\
\hline & 80 & 55.95 & 58.36 & 4.33 & 5.60 & 26.40 & 19.33 \\
\hline & 90 & 62.24 & 64.93 & 4.82 & 6.23 & 29.37 & 21.51 \\
\hline & 100 & 68.53 & 71.51 & 5.30 & 6.86 & 32.34 & 23.69 \\
\hline
\end{tabular}




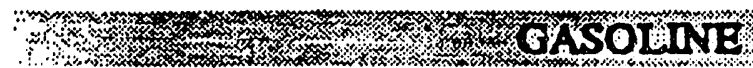

\section{Calorific Coonent:}

47.7 MS/k8

Specific Gravity:

$0.75 \mathrm{~kg} / \mathrm{lict}$

Dalivirod Cod

Foodstock

15.73

0-5 kin

$50 \mathrm{~km}$

$100 \mathrm{~km}$

$300 \mathrm{bm}$
15.73

15.73

15.73
Transport

USchiter

0.16

0.54

0.92

2.48
Total

15.89

16.27

16.65

18.20 

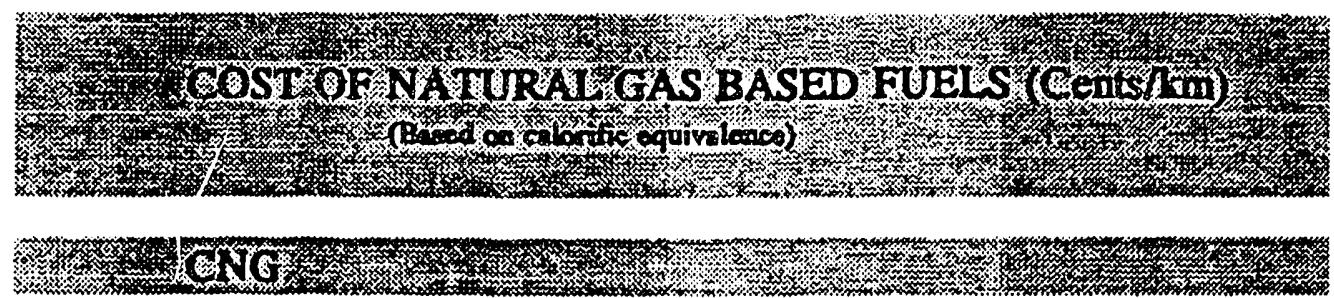

$\begin{array}{llll}\text { Calorific } & 1 & 1 \text { licer gasoline }= & 33.9 \text { cf Natural Gas } \\ \text { Equivaleace } & \text { I } & 1 \text { liter diesel }= & 36.4 \text { cf Natural Gas }\end{array}$

\begin{tabular}{|c|c|c|c|c|c|c|}
\hline \multicolumn{2}{|c|}{ FAST IIIT } & $\begin{array}{ll}P \\
k\end{array}$ & ructs & Hen & 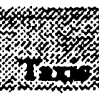 & 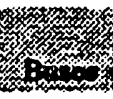 \\
\hline \multirow{4}{*}{$0-5 \mathrm{~km}$} & & $-\cdots$ & ats per $k$ & & 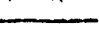 & \\
\hline & Delivered Fuel & 1.365 & 1.766 & 8.575 & 1.365 & 6.281 \\
\hline & Coover & 1.131 & 1.390 & 3.329 & 0.255 & 1.101 \\
\hline & Total Cost & 2.496 & 3.156 & 11.904 & 1.620 & 7.381 \\
\hline
\end{tabular}

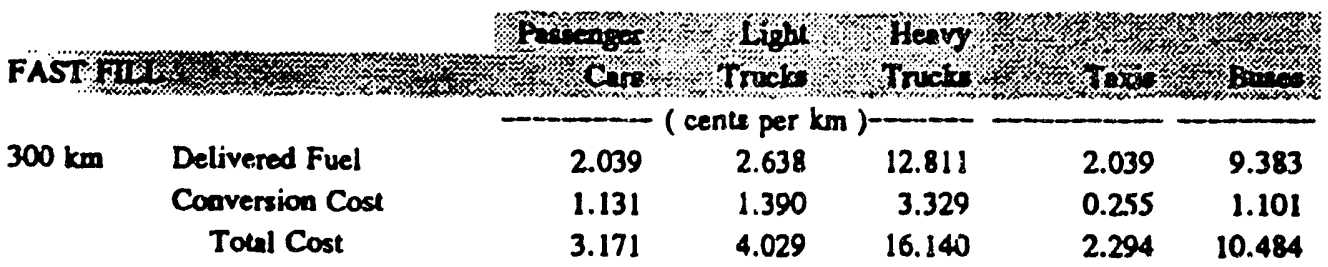

\begin{tabular}{|c|c|c|c|c|c|c|}
\hline \multicolumn{2}{|c|}{$\mathrm{TRI}$} & \multicolumn{2}{|c|}{ 篗 } & 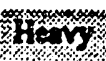 & \multicolumn{2}{|c|}{ L } \\
\hline \multirow{4}{*}{$0-5$ bed } & & & & & & \\
\hline & Delive & 0.935 & 1.209 & 5.872 & 0.935 & 4.30 \\
\hline & Conve & 1.131 & 1.390 & 3.329 & 0.255 & 1.101 \\
\hline & Tot & 2.066 & 2.600 & 9.201 & 1.189 & 5.40 \\
\hline
\end{tabular}

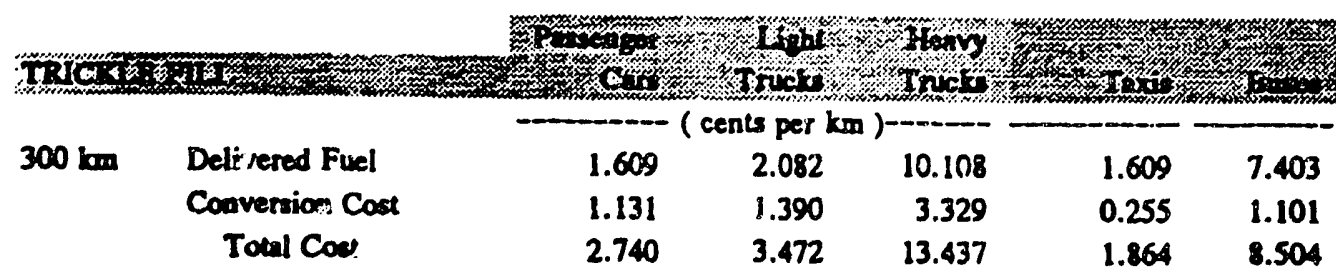




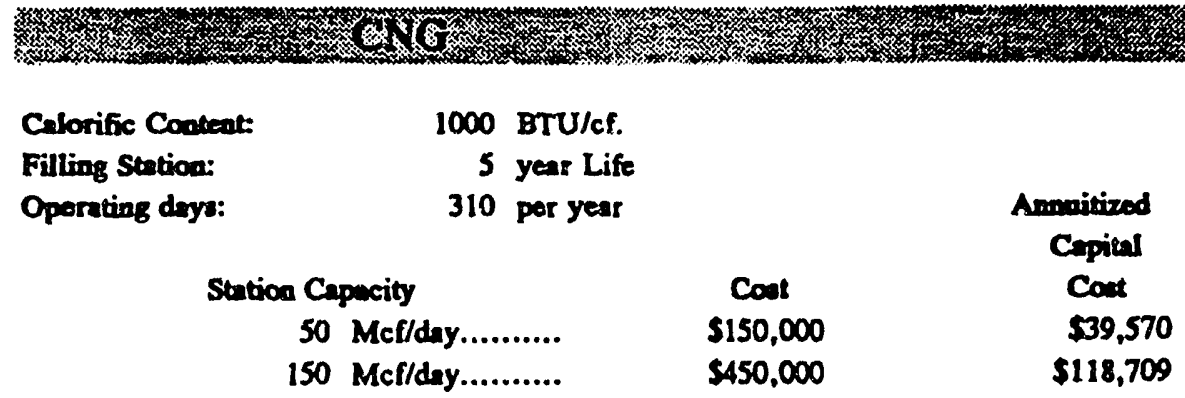

Delivered CNG Cost for 50 Maf Copecity Stution (Fust-Fill)

\begin{tabular}{|c|c|c|c|c|c|c|}
\hline & & & STS PEE & & & \\
\hline & Capital & & $\boldsymbol{\$ 2 . 5 5}$ & & & \\
\hline & Feedstock & & $\$ 1.25$ & & & \\
\hline & Operating & & $\$ 1.40$ & & & \\
\hline Traspont & Cost & & & & ckle Fill & \\
\hline & $0 \mathrm{~km}$ & (at gate) & $\$ 5.20$ & & $\$ 3.56$ & \\
\hline$\$ 0.53$ & $50 \mathrm{~km}$ & & 55.73 & & $\$ 4.09$ & \\
\hline 50.93 & $100 \mathrm{~km}$ & & $\$ 6.13$ & & $\$ 4.49$ & \\
\hline$\$ 2.57$ & $300 \mathrm{~km}$ & & $\$ 7.77$ & & $\$ 6.13$ & \\
\hline Vehicle & 1 & & Light & Heavy & & \\
\hline & & Cars & Trucks & Trucks & Taxis & Buses \\
\hline Cost & & $\$ 1,000$ & $\$ 1,800$ & $\$ 4,500$ & $S 1, B$ & $\$ 4,500$ \\
\hline $\mathrm{Km} /$ Year & & 12,000 & 19,000 & 22,000 & 96,0 is & 60,000 \\
\hline Annuitized & $\cos t / y r$ & $\$ 136$ & $\$ 264$ & $\$ 732$ & 124. & $\$ 660$ \\
\hline & per km & $\$ 0.011$ & $\$ 0.014$ & $\$ 0.033$ & 50.003 & $\$ 0.011$ \\
\hline
\end{tabular}




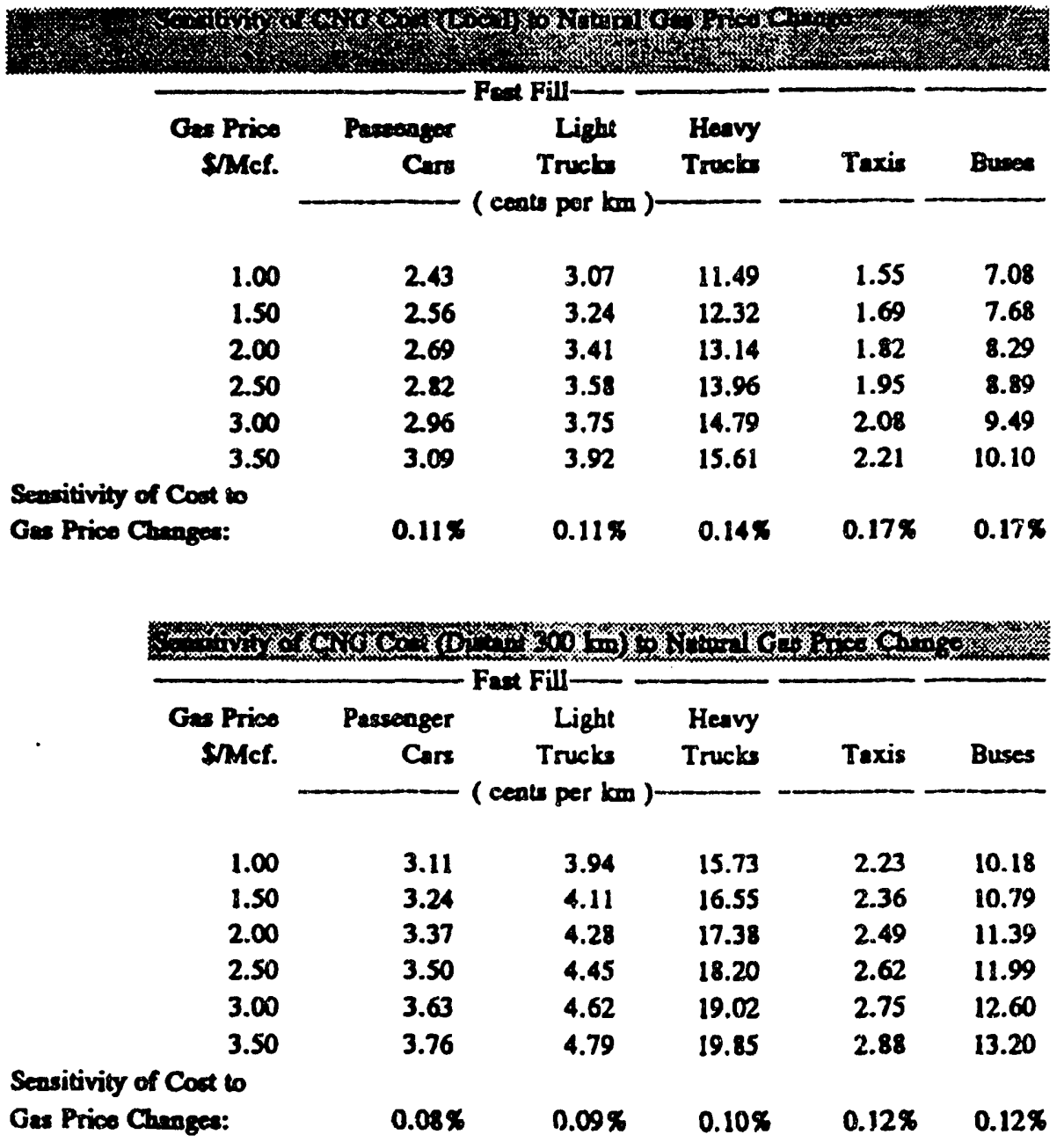




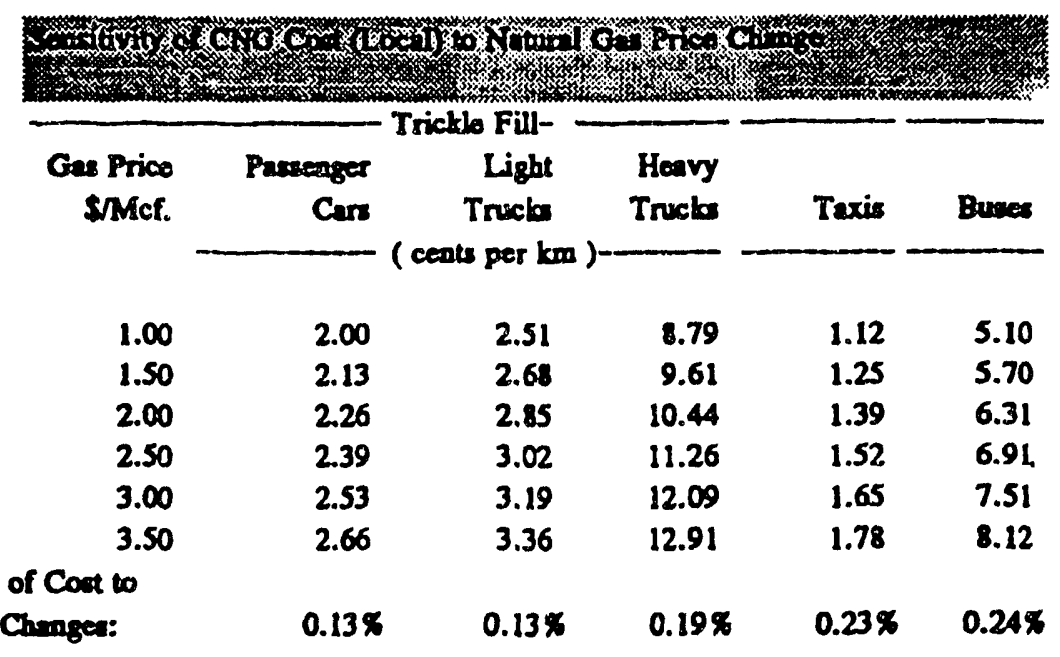

Sensitivity of Cost to

Gas Price Chengen:

$0.13 \%$

$0.19 \%$

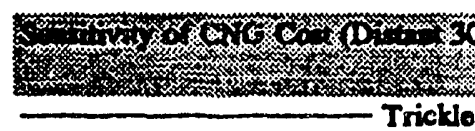

\begin{tabular}{|c|c|c|c|c|c|}
\hline $\begin{array}{l}\text { Gas Price } \\
\text { SMcf. }\end{array}$ & $\begin{array}{r}\text { Paracager } \\
\text { Cars }\end{array}$ & $\begin{array}{l}\text { Light } \\
\text { Truelo }\end{array}$ & $\begin{array}{l}\text { Heavy } \\
\text { Tructo }\end{array}$ & Taxis & Burea \\
\hline 1.00 & 2.67 & 3.39 & 13.03 & 1.80 & 8.20 \\
\hline 1.50 & 2.81 & 3.56 & 13.85 & 1.93 & 8.81 \\
\hline 2.00 & 2.94 & 3.73 & 14.67 & 2.06 & 9.41 \\
\hline 2.50 & 3.07 & 3.90 & 15.50 & 2.19 & 10.01 \\
\hline 3.00 & 3.20 & 4.07 & 16.32 & 2.32 & 10.62 \\
\hline 3.50 & 3.33 & 4.24 & 17.15 & 2.45 & 11.22 \\
\hline
\end{tabular}

Sensitivity of Cost to Gas Price Chengea:
$0.10 \%$
$0.10 \%$
$0.13 \%$
$0.15 \%$
$0.15 \%$ 

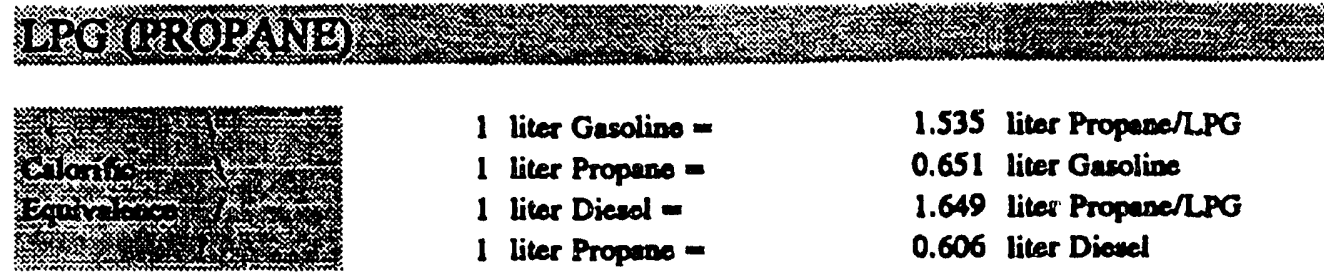

1.535 liter Propane/LPG

0.651 liter Gasoline

1.649 liter Propane/LPG

1 liter Propano -

0.606 liter Diovel

\section{$0-5 \mathrm{~lm}$
Delivered Fuel
Coaversion Cost Total Cost
$300 \mathrm{~km}$ Delivered Fuel
Conversion Cost Total Cost

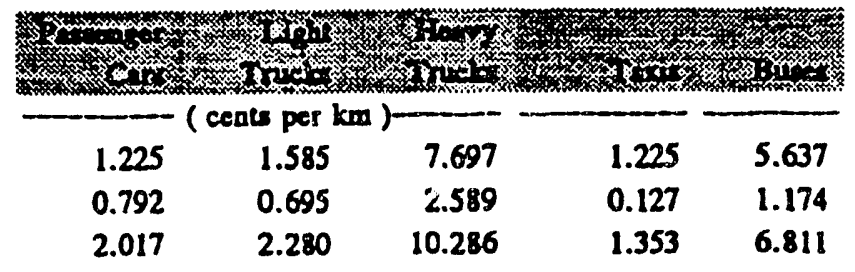

\begin{tabular}{|c|c|c|c|c|}
\hline W & Yrot & Mut & 1 & 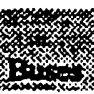 \\
\hline \multicolumn{5}{|c|}{ - (cents per kra )- } \\
\hline 1.520 & 1.966 & 9.547 & 1.520 & 6.992 \\
\hline 0.792 & 0.695 & 2.589 & 0.127 & 1.174 \\
\hline 2.312 & 2.661 & 12.137 & 1.647 & 8.167 \\
\hline
\end{tabular}




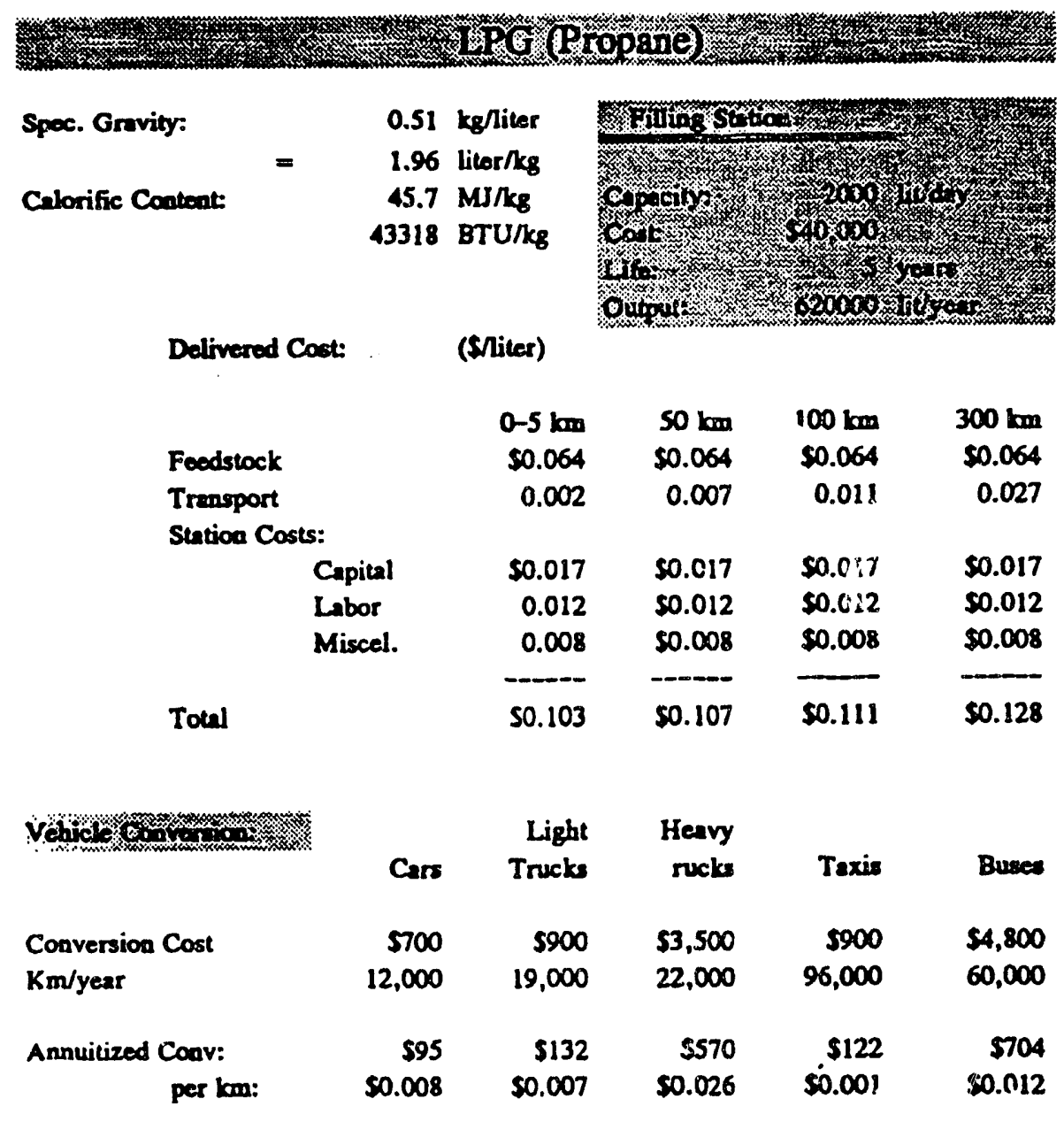




\begin{tabular}{|c|c|c|c|c|c|}
\hline $\begin{array}{l}\text { Gas Price } \\
\text { SMAcf. }\end{array}$ & $\begin{array}{r}\text { Parcenger } \\
\text { Cars }\end{array}$ & $\begin{array}{l}\text { Light } \\
\text { Truclo }\end{array}$ & $\begin{array}{l}\text { Heavy } \\
\text { Trucles }\end{array}$ & Taxis & Buses \\
\hline 1.00 & 1.87 & 2.08 & 9.34 & 1.20 & 6.11 \\
\hline 1.50 & 2.17 & 2.48 & 11.24 & 1.50 & 7.51 \\
\hline 2.00 & 2.47 & 2.87 & 13.14 & 1.81 & 8.90 \\
\hline 2.50 & 2.77 & 3.26 & 15.04 & 2.11 & 10.29 \\
\hline 3.00 & 3.08 & 3.65 & 16.94 & 2.41 & 11.69 \\
\hline 3.50 & 3.38 & 4.04 & 18.85 & 2.72 & 13.08 \\
\hline \multicolumn{6}{|l|}{ Coat to } \\
\hline onneex. & $0.32 x$ & $0.38 x$ & $0.41 \%$ & $0.50 x$ & $0.46 \%$ \\
\hline
\end{tabular}

Sensitivity of Coat

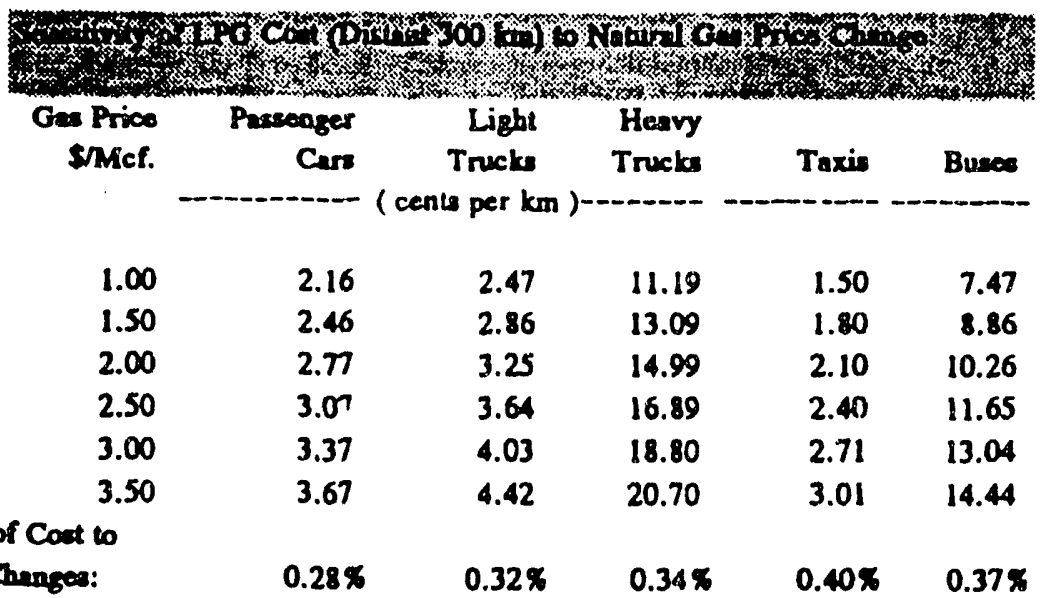

Sensitivity of Cout to

Gas Price Changea:

$0.28 \%$ 


\begin{tabular}{|c|c|c|}
\hline $\begin{array}{l}\text { Specific Gravity: } \\
\text { Calorific Content: }\end{array}$ & $\begin{array}{l}0.8 \text { kg/licer } \\
20.02 \text { MJ/kg }\end{array}$ & \\
\hline \multicolumn{3}{|c|}{ Wlo } \\
\hline Capecity (tond/day) & 1200 & 2500 \\
\hline Service Factor & $81 \%$ & $81 \%$ \\
\hline Production (Tons/year) & 354,780 & 739,125 \\
\hline Capital (1986 USS million) & 207 & 349 \\
\hline Gas Foodstock Mcf/ton meth. & 32 & 32 \\
\hline O \& M (\$ million/year) & 14 & 26 \\
\hline
\end{tabular}

Co.

\begin{tabular}{|c|c|c|}
\hline Capital Cost & 576.71 & $\$ 62.08$ \\
\hline Gas Foedstock & 40.00 & 40.00 \\
\hline$O \& M$ & $\$ 39.46$ & $\$ 35.18$ \\
\hline Total plant gate: & $\begin{array}{l}\$ 156.17 \text { /tod } \\
\$ 0.156 \pi \mathrm{kg} \\
\$ 0.125 \text { /liter }\end{array}$ & $\begin{array}{r}\$ 137.26 \\
\$ 0.137 \\
\$ 0.110\end{array}$ \\
\hline
\end{tabular}

M9O BL

Methrnd Plant Capacity:

1200

2500

$\begin{array}{lrrr}\text { Methanol } & 90 \% & \$ 0.112 & \$ 0.099 \\ \text { Gasoline } & 10 \% & 0.016 & 0.016 \\ \text { Blending Cost } & & 0.011 & 0.011 \\ & & \$ 0.140 & \$ 0.126\end{array}$

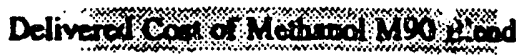

Blend

Filling Station Cost

TOTAL

$\begin{array}{ll}T r & \text { cliter } \\ \text { Distance } & 0.164 \\ 0-5 \mathrm{~km} & 0.544 \\ 50 \mathrm{~km} & 0.924 \\ 100 \mathrm{~km} & 2.476 \\ 300 \mathrm{~km} & \end{array}$

Vefc

Conversion Cost

$\mathrm{Km}$ /year

Annuitized Conv:

per km:
US cents per liter

13.957

2.576

16.533

Cost at Dalivery Point (US cents per liter;

16.697

17.077

17.457

19.009

12.595

2.576

15.171

15.335

15.715

16.095

17.647

\section{Light \\ Henvy}

Trucka

$\$ 500$

19000

rucks

$\mathbf{\$ 3 , 2 0 0}$

22000

573

$\$ 521$

$\$ 0.024$

Taxis
$\$ 500$
96000
$\$ 68$
$\$ 0.001$

Buren

$\$ 4,300$

60000

$\$ 631$

$\$ 0.004$

$\$ 0.011$ 


\section{MEHHOLONOO)}

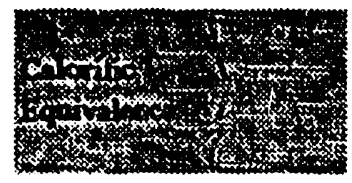

1 liter Gasoline -
1 liter Methnnol =
1 liter Diesel =
1 litar Methnnol =

\subsection{4 liter Mothnaol \\ 0.448 liter Oasoline \\ 2.400 liter Methanol \\ 0.417 liker Diesel}

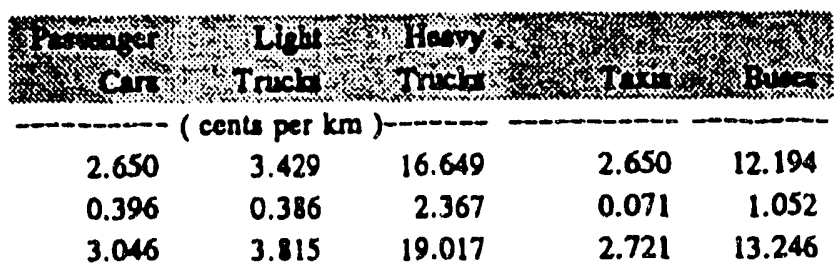

$300 \mathrm{~km}$

Delivered Fuel
Conversion Cost
Total Cost
Delivered Fuel
Convernion Cost Total Cost

Total Cost

\begin{tabular}{|c|c|c|c|c|}
\hline 1 & Truch & Trovolo & $k_{k}$ & ${ }_{3}$ \\
\hline & ( cents per $k$ & & & \\
\hline 3.050 & 3.945 & 19.159 & 3.050 & 14.032 \\
\hline 0.396 & 0.386 & 2.367 & 0.071 & 1.052 \\
\hline 3.446 & 4.332 & 21.527 & 3.121 & 15.084 \\
\hline
\end{tabular}

